ارائه روش نوين اولويتبندى راهبردهاى مقابله با بيابانزايى بر اساس تصميم گيرى جندمعياره

$$
\text { محمد حسن صادقىروش }
$$

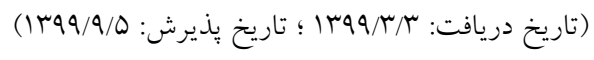

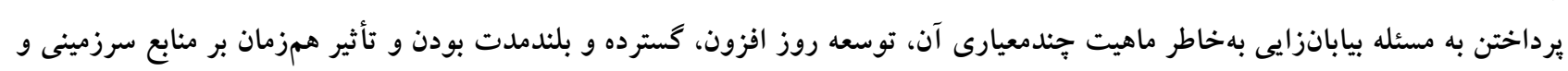

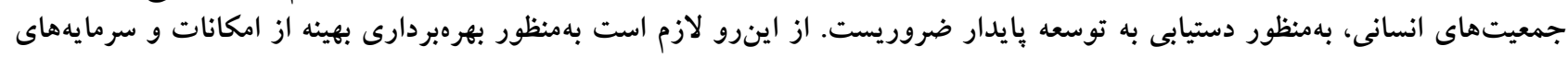

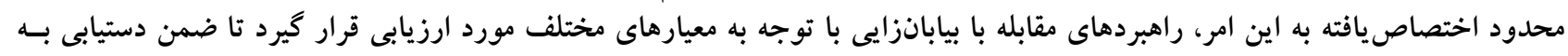

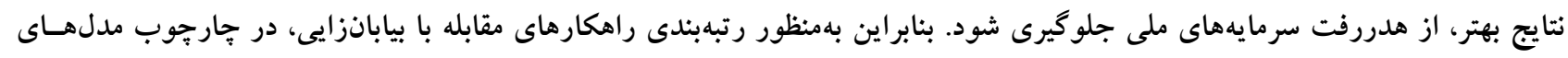

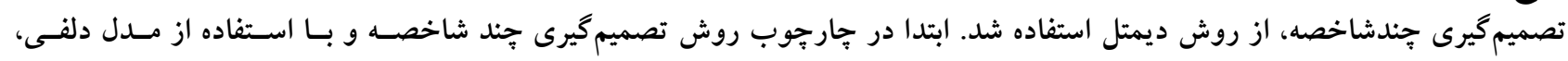

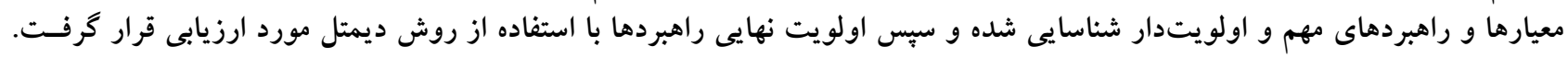

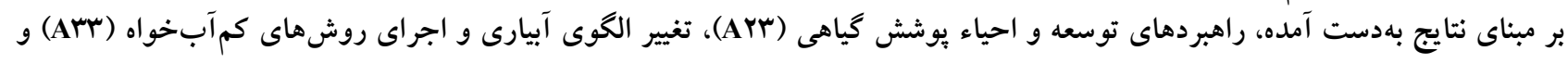

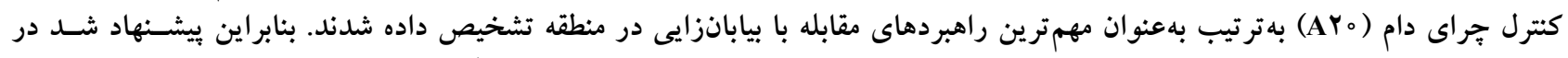

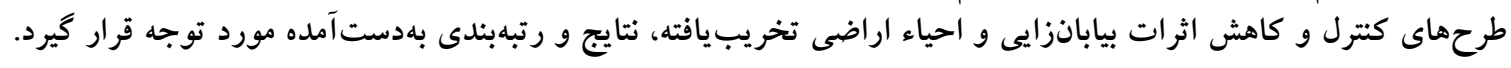

وازههاى كليدى: مقابله با بيابانزايى، روشهاى تصميمگيرى جندمعياره، مدل ديمتل، مقايسه زوجى 
مناطق بيابانى و افزايش ضريب موفقيـت در اجــراى طـرحهـاى

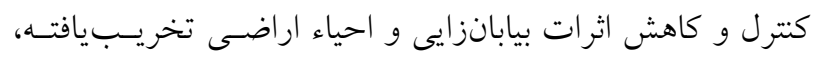

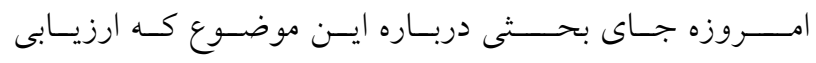

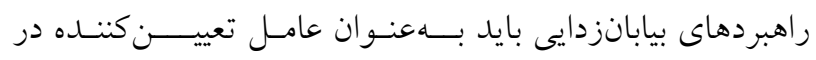
يروزههاى اجرايى مدنظر قرار گيرد، نمانده است. در دشت يزد- خضر آباد نيز با توجـه بـهـ اينكسه بـيش از 19

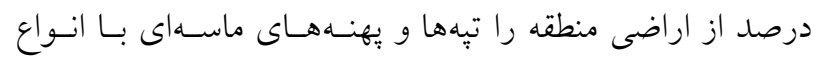
رخسارههاى تخريبى و فرسايشى شكل داده و كل اراضى، تحت

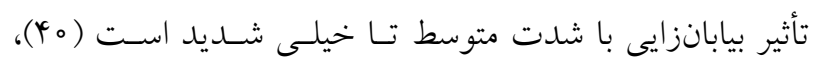

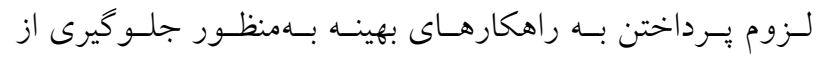
بيابانى شدن يا احياء و ترميم مناطق تخريبيافته، ضرورى بهنظر

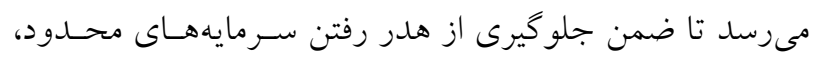
بازدهى طرحهاى كنترل و احياء عرصههاى طبيعى بالا رود. از جمله تحقيقات انجامشده در زمينه بهكارگيرى مــلهـــاى تصـميم گيـرى (Decision Making Models) بــراى ارائـهـ

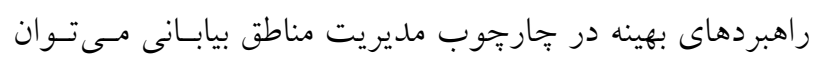

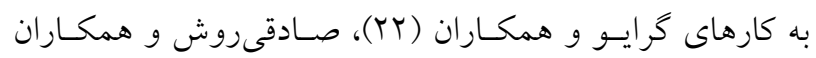
(D) צr.

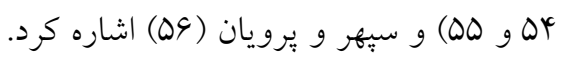

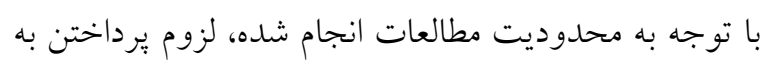

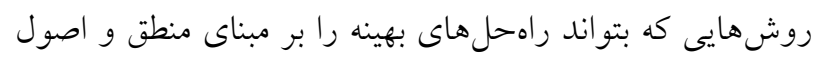

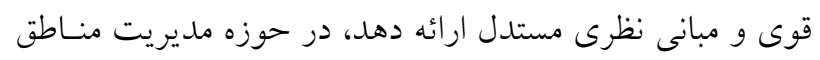

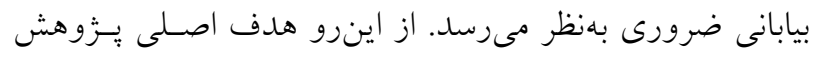

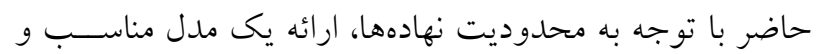

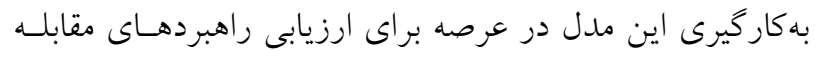
با بيابانزايى در جارجوب مديريت بايدار مناطق بيابـانى اسـت. براى دستيابى به اين هدف، در جارجوب مدلهاى تصميم گيرى جندشاخصـه Multi Attribute Decision Making Models) بر اسـاس مقايسهـهـاى زوجسى، تكنيـى آزمايشـاه

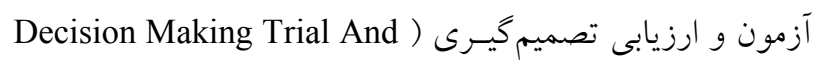
(DEMATEL =Evaluation Laboratory راهكارهاى مقابله با بيابانزايى مدنظر قرار گرفت. اين درحسالى

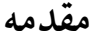

بيابانزايى عبارتست از تخريب اراضى در نواحى خشك، نيمـهـخشك و خشك نيمهمرطوب كه در نتيجـه عوامـل كونـاكون از

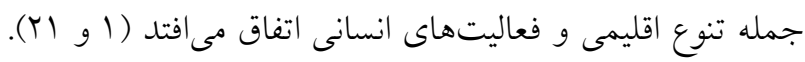

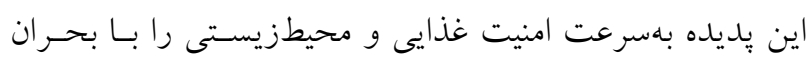

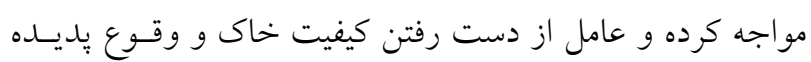

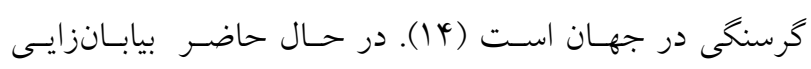
بهعنوان يكى معضل كريبان كير بسـيارى از كشـورهاى جهـان از

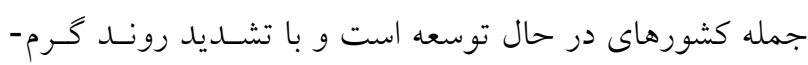

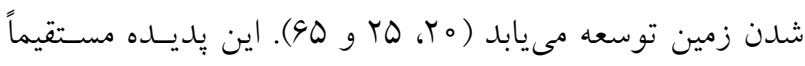

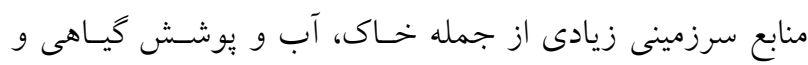

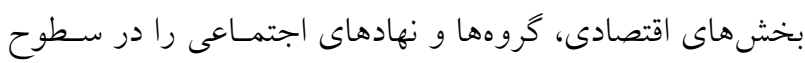

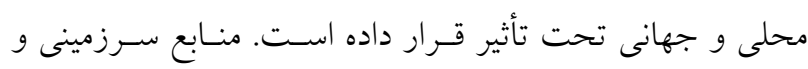

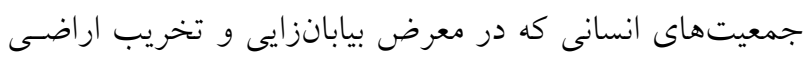

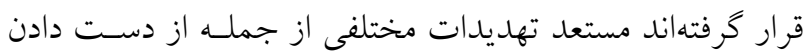

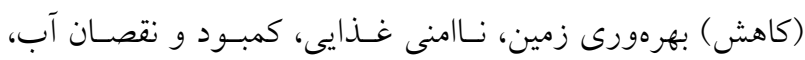
مشكلات اقتصادى، محروميتهاى اجتماعى و خطرات سـلامتى

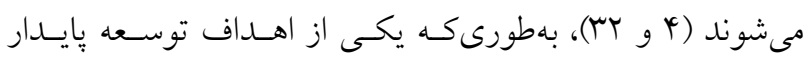
كـه در كنفــانس (SDG =Sustainable Development Goal) ريو در سال rol ro مطرح شد "دستيابى به حفاظت، احيـاء و

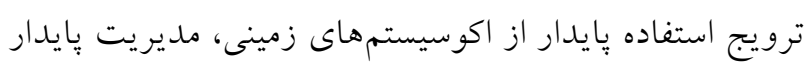

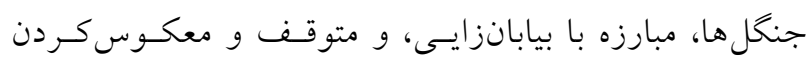

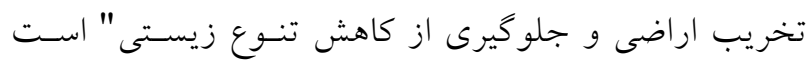

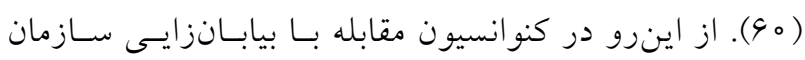

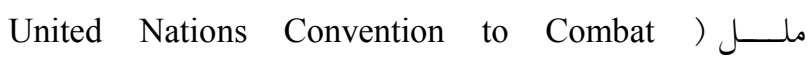
(UNCCD =Desertification مناسب و درخور در مقابله با تهايدات جهانى و بيابـانزايسى و

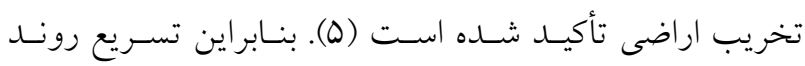

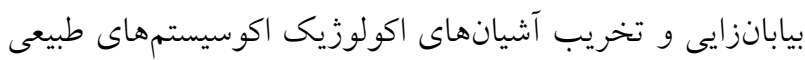

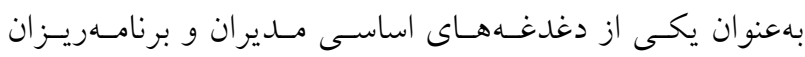

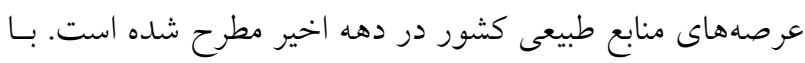

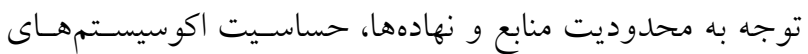


اهميت و وزن هر عامل در سيستم نيز در نهايت نهفـط توسطط

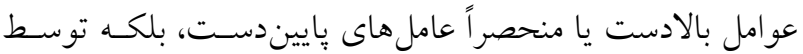
تمام عوامل موجود در سيستم (و بهعبارتى كل مدل) تعيين مى -

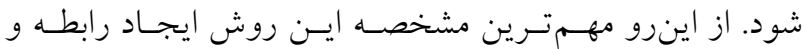
ساختار بين عوامل است. يذيرش روابط انتقالنإِــير و توانـايى نمايش كليه بازخورهاى ممكن نيز از دلايـل برتسرى ايـن شسيوه نسبت به ساير شيوههاى متكى به نظريه كرافهاست (9 و مَ). اين تكنيك اولين بار توسط كابوس و فـونتلا ( Gabus and (Fontela) در اواخر سال (9V) بهطور عمده براى بررسى مسائل بسيار يِيجيده جهانى و استفاده از قضاوت خبر گان ارائه شد (10)

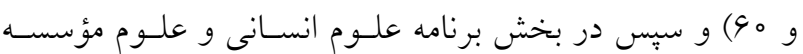
باتل مموريال (Battelle Memorial) در سالهاى $19 V 4$ الت $19 V 9$ كسترش يافته و در راستاى تحقيق و حل بيجيده مسائل گروهى

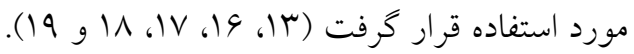

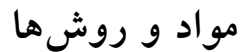

معرفى منطقه مورد مطالعه

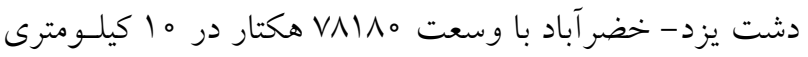

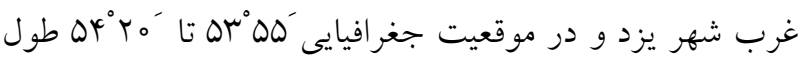

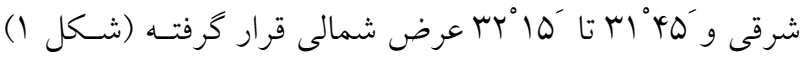

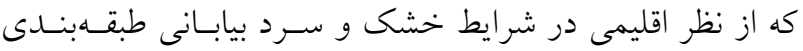
مىشود. متوسط بارنـــى سـاليانه |Y| ميلـىمتـر و جهـت بـاد

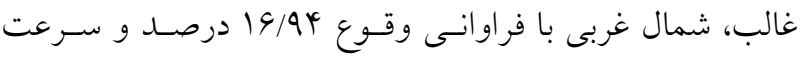

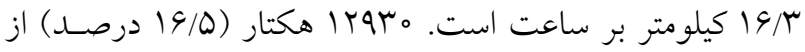

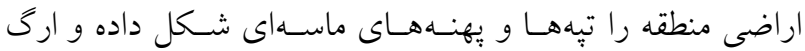
بزرگ اشكذر با وسعتى معادل سr (Erg) با انواع رخسارههاى تخريبى و فرسايشى بـهـشــم مسى خـورد كـه.

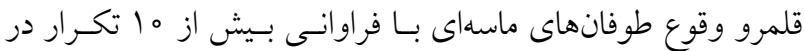
سال با جهت غالب غربى و شمال غربى است. در عين حال از كـل اراضى زراعى منطقه 1990 هكتار (Q/Q T درصد) را اراضى مخرويسه حاصل از عمليات انسانى و فرايندهاى طبيعى تشكيل داده (ب) كـهـ نشـاندهنــده وضـعيت كـاملاً خـاص آن از نظركـاه بيابـانزايسى و
است كه هيج سابقهاى از كاربرد مدل ديمتـل در حسوزه مسـائل مربوط به مديريت مناطق بيابانى و از جمله انتخاب سيستماتيك راهبردهاى بهينه در فرايند مقابله بـا بيابـانزايسى جـهـ در داخـل ايران و جهه در خارج از ايران مشـهاهد نشــ، هرجنــد در سـاير

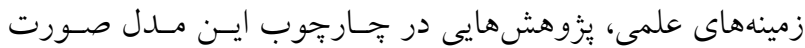

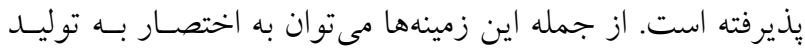

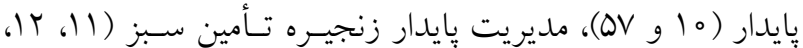
TY، צY و Q99)، بررسى عوامل مـؤثر بـر رضـايت مشـتريان (T9)،

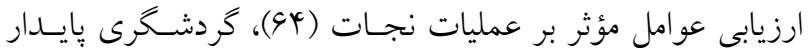

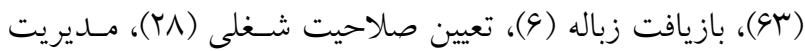

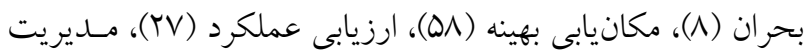

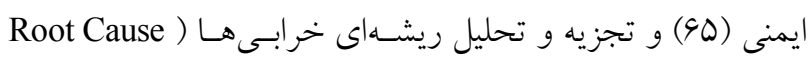
(V) (RCFA =Failure Analysis تكنيك آزمايشگاه آزمون و ارزيابى تصميم گيـرى يـا ديمتـل

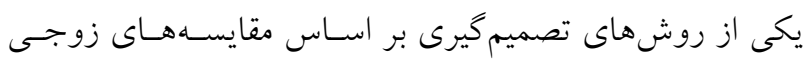

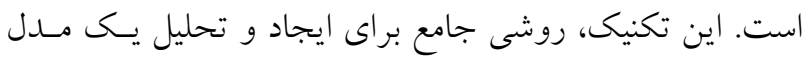

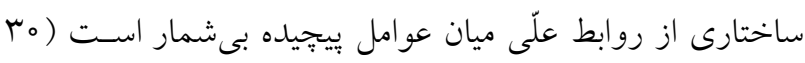

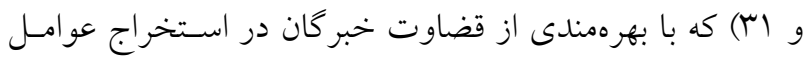
يكى سيستم و ساختاردهى نظاممند به آنها با بهكـاركيرى اصـول

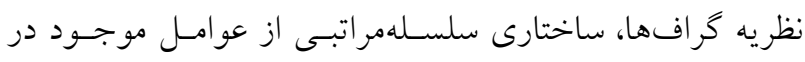
سيستم همراه با روابط تأثير و تأثر متقابل عناصر مذكور را ارائسه. ميدهد، بهكونهاى كه شدت اثر روابط مذكور را بهصـورت امتيـاز

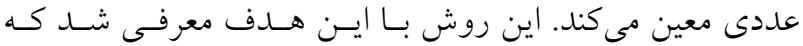
استفاده مناسب از روشهاى تحقيـق علمسى مسىتوانـــ سـاختار ييجيده مسائل را بهبود بخشد و در شناسايى راهحل هـاى عملى با استفاده از ساختار سلسـلهمراتبسى مشـاركت نمايســ (9 و 94). يكسى از امتيـازات روش ديمتـل نسـبت بـه سـاير روشهــاى

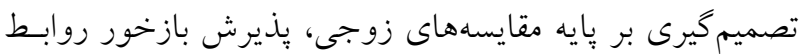
است، يعنى در ساختار سلسله مراتبى حاصل، هر عنصر مىتواند برايه

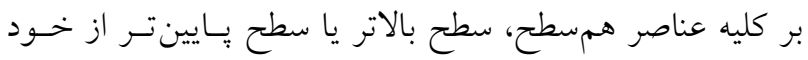
تأثير بخذارد و متقابلاً از تكتك آنها تأثير بيذيرد. به بيـان ديخـر عناصر موجود در سيستم مى توانند مسـتقل از همــيخر نباشـند. 

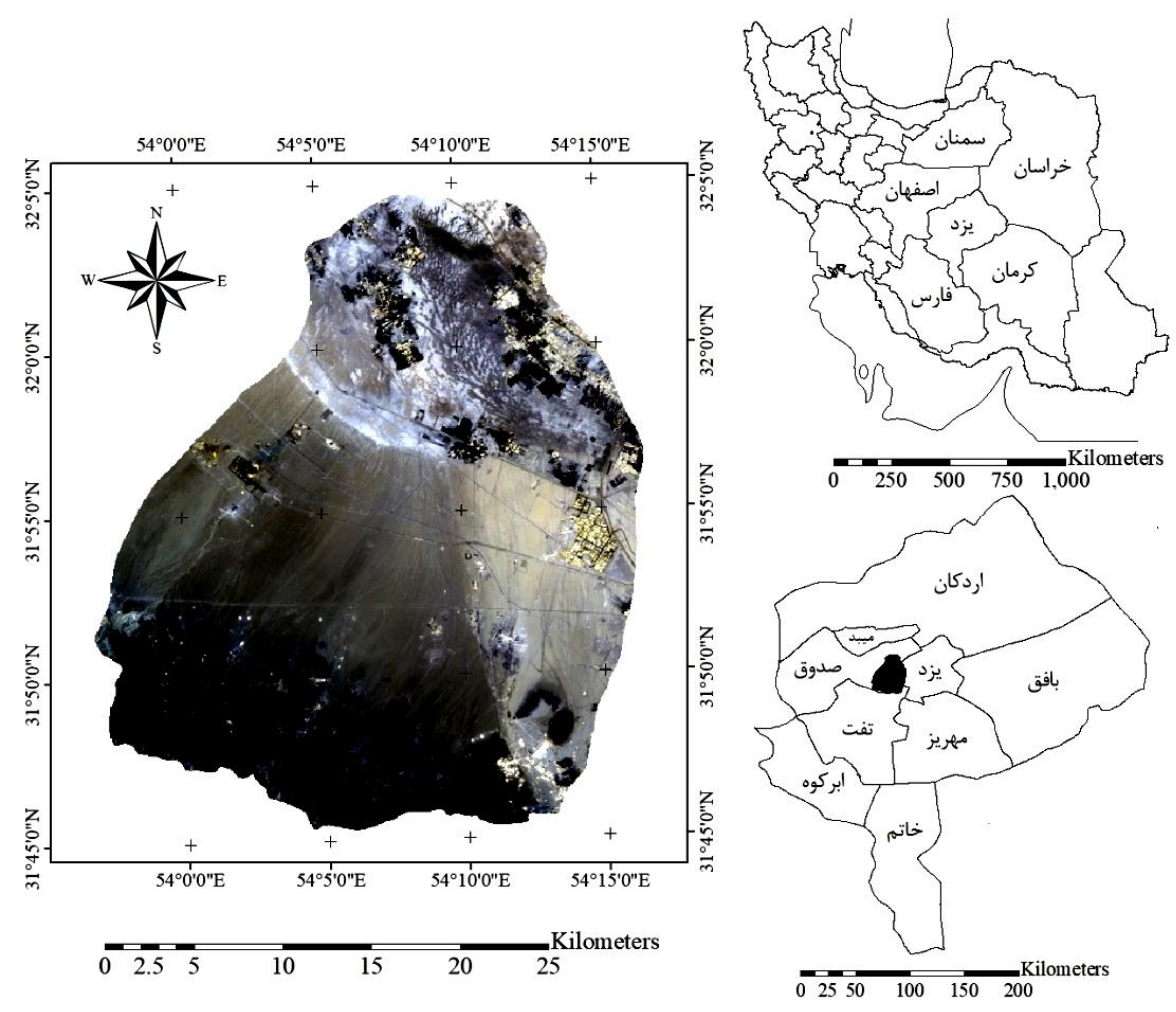

شكل ا. موقعيت دشت يزد - خضر آباد (رنغى در نسخه الكترونيكى)

بودند و همجنين نسبت به منطقه و مسائل مربوط به آن اشـراف

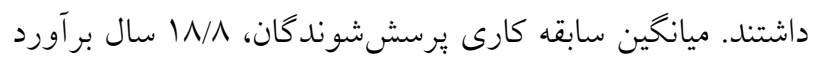
شد. \| نفر از برسـش شـوندكان داراى مــرك دكتـرى، ه نفـر كارشناس ارشــ و ه نفـــ كارشـناس شـامل كارشناسـان مركـز تحقيقات و آموزش كشـاورزى و منـابع طبيعى سـازمان جهـاد كشاورزى اسـتان يـزد، ايستخاه تحقيقـات بيابـانزدايسى شهـيد صدوقى اشكذر، مديريت جهاد كشاورزى شهرسـان صـدوق و يزوهشكده مناطق خشك و بيابانى دانشخاه يـزد بودنــد. روايسى صورى ثيرسشنامه در بزوهش حاضر با بهرهمندى از (Validity)

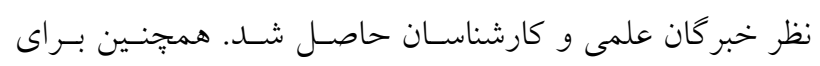

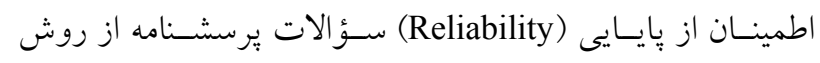

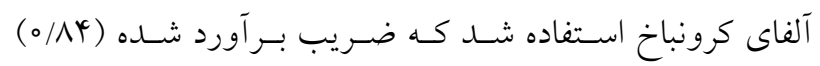
بيانگر بايايى بالا در طراحى برسشنامه بود.

برآورد وزن نسبى معيارهـا و راهبردهـا و تشـكيل مـاتريس مقايسات زوجى (Pairwise) گروهى

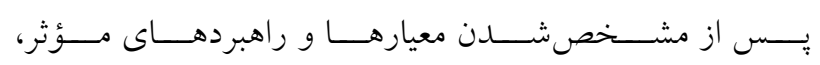

بيانكننده لزوم برداختن به راهحل هاى مقابله بـا بيابـانزايسى در ايسن حوزه است.

روش مطالعه بهطور خلاصه مراحل به كاركيرى تكنيك ديمتل به ترتيـب زيـر

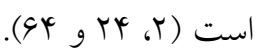
انتخاب معيارها و راهبردهاى مؤثر انتخاب معيارها و راهبردها از ميان طيـف وسـيعى از معيارهـا و

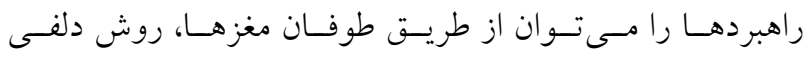
(Nominal Group Technique) يا روش گروه اسمى (Delphi)

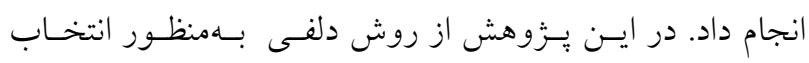
معيارها و راهبردهاى مهم و اولويتدار و تشكيل ساختار سلسله تسرون

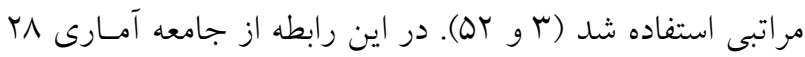

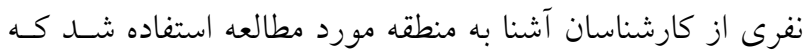
حداقل داراى درجه كارشناسـى (تخصـص) در زمينـه مـديريت مناطق بيابانى و رشتههاى وابسته مانند آبخيـزدارى و مرتـعدارى 
در نحوه قضاوت بايد تجديد نظر شود (rT).

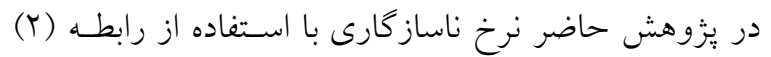

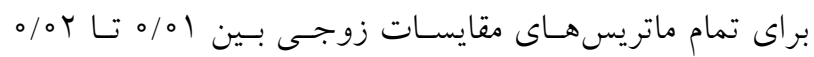

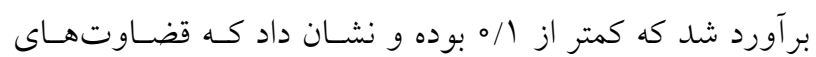
انجامشده از بايايى مناسبى برخوردار است.

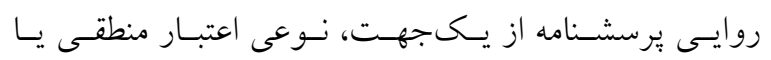

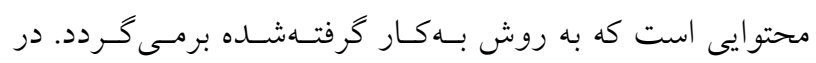

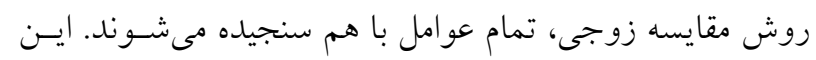

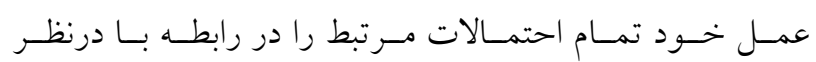

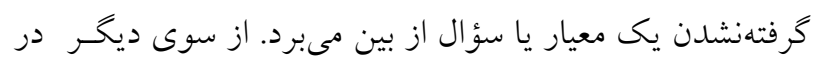

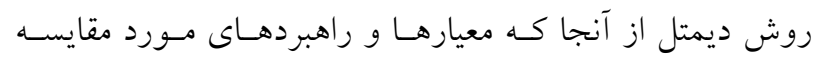

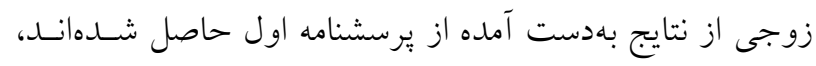
ارزيابى روايى در اين مورد موضوعيت بيدا نمى كند.

\section{تعيين شدت اثر اوزان معيارها و راهبردها} - تعيين اثر معيارها بر يكديخر در ارتباط با هدف تهن در اين مرحله بهمنظور تعيين معيارهاى مؤثر، ماتريس مقايسـات

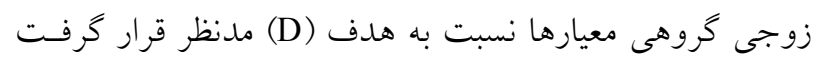
و مراحل زير بر روى ماتريس مذكور انجام شد.

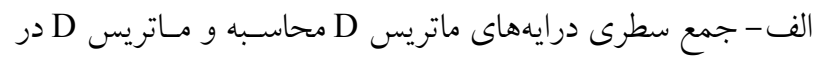

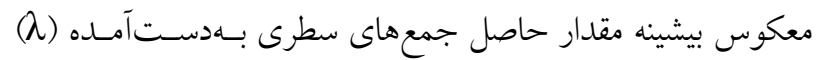

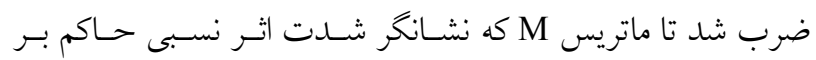
رابطههاى مستقيم موجود در سيستم است بهدست آيد (رابطه ب). $\mathrm{M}=\lambda * \mathrm{D}$

ب- ماتريس S Sه نشانكر شـــت اثـر نسـبى حساكم بـر روابـط

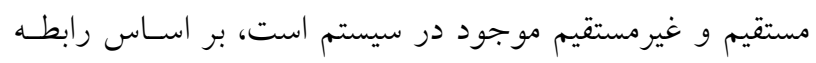

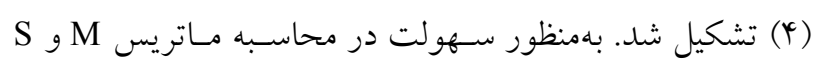

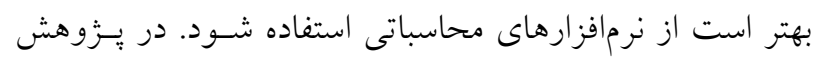
حاضر از نرم|فزار صفحه كسترده Excel استفاده شد. $\mathrm{S}=\mathrm{M}(1-\mathrm{M})^{-1}$

ج- در ماتريس S جمع سطرى (R) و سـتونى (J) درايسههـا و

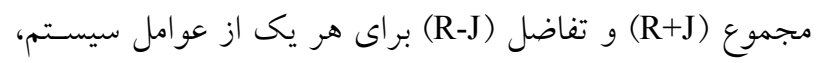

بهمنظوردستيابى به وزن نسبى (Local Priority)، عناصر تصميم

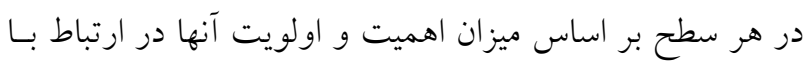

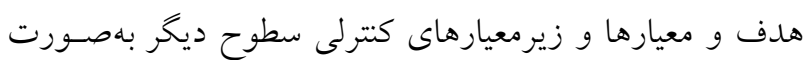

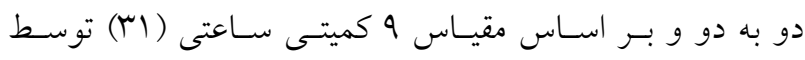

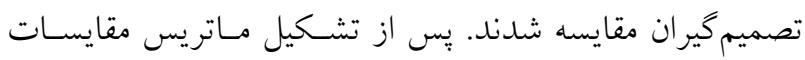

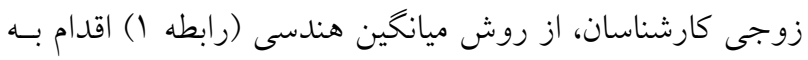

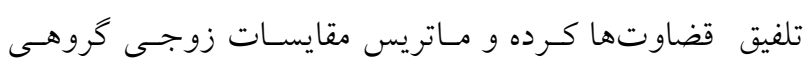

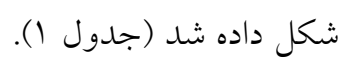

$$
\overline{\mathrm{a}}_{\mathrm{ij}}=\left(\pi_{\mathrm{k}=1}^{\mathrm{N}} \mathrm{a}_{\mathrm{ij}}{ }^{\mathrm{k}}\right)^{\frac{1}{\mathrm{~N}}}
$$

در اين رابطه،

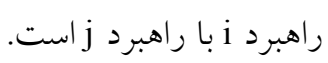

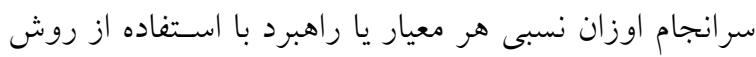

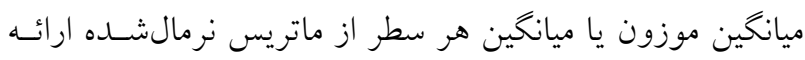

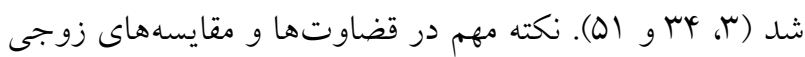

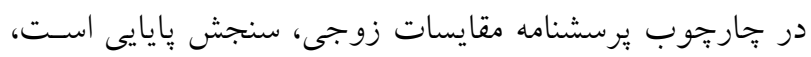

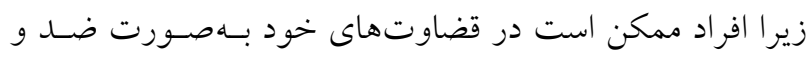

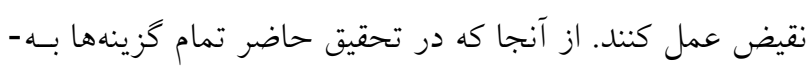

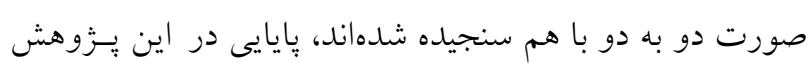

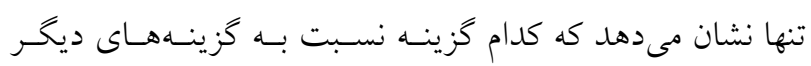
برترى دارد، زيرا ضريب بالا زمانى حاصل مىشود كه مخاطبـان

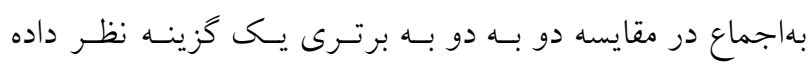

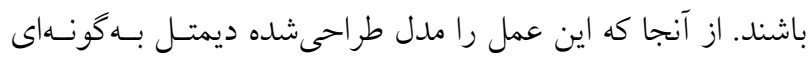

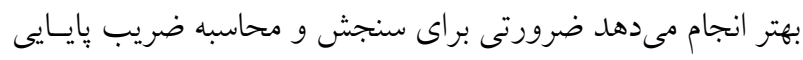

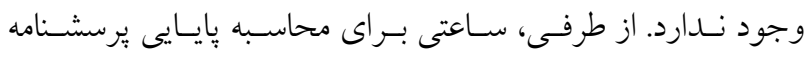

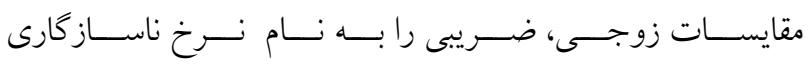
(I.R. =Inconsistency Ratio) شـاخص سـازكًارى (C.I. =Consistency Index) بـه شـاخص نس تصـادفى بـودن (R.I.I. =Random Inconsistency Index) حاصـل

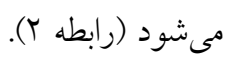

$\mathrm{IR}=(\mathrm{CI}) / \mathrm{IIR}$

نرخ ناساز كارى براى هر ماتريس مقايسه زوجى محاسبه و ارائه

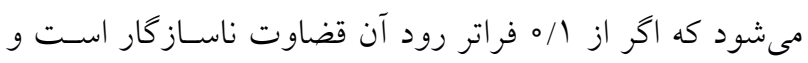




\begin{tabular}{|c|c|c|c|c|c|}
\hline \multirow{3}{*}{$\mathrm{D}=$} & $\mathrm{a}_{11}$ & $\mathrm{a}_{12}$ & ........... & $\mathrm{a}_{1 \mathrm{n}}$ & \multirow{3}{*}{$\begin{array}{c}A=\left[a_{i j}{ }^{\dagger}\right], i=1,2, \ldots . . m \\
j=1,2, \ldots . n\end{array}$} \\
\hline & $\mathrm{a}_{21}$ & $\begin{array}{l}\mathrm{a}_{22} \\
:\end{array}$ & ........... & $a_{2 n}$ & \\
\hline & $\mathrm{am}_{\mathrm{m} 1}$ & $a_{\mathrm{m} 2}$ & ................. & $\mathrm{a}_{\mathrm{mn}}$ & \\
\hline
\end{tabular}

m: تعلاد رتبه راهبردها (i)، n: تعداد معيارها (j) و aij ترجيح عنصر iام نسبت به عنصر jام است.

- تعيين اثر راهبردها بـر يكـديخر در ارتبـاط بـا مجموعسه معيارها و تعيين مؤثرترين راهبردها در دستيابى به هدف به اين منظور در ابتدا ماتريس مقايسات زوجى راهبردها نسـبت به هر معيار در ارزش همان معيار از رابطه (هD) بـهدسـت آمـــ (جدول r) و سبس بر مبناى ايسن جــاول، مـاتريس مقايسـات زوجى ميـانخين ارزش تـأثير راهبردهـا در مجمـوع معيارهـا بـا

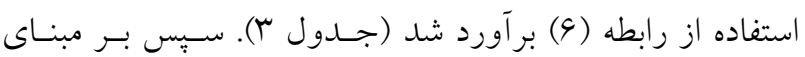

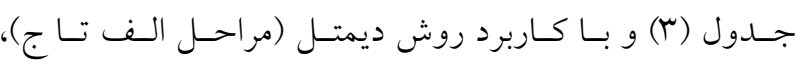
ماتريس ترتيب نفوذ راهبردها بر يكديخر در ارتباط بـا مجمـوع

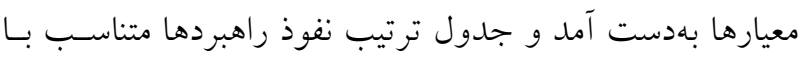

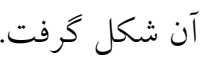

$\mathrm{P}_{\mathrm{ij}}=\mathrm{D}_{\mathrm{ij}} * \mathrm{~W}_{\mathrm{j}}$

در اين رابطه: - - ماين

مقدار وزنى نرمال كه هر معيار در ارتباط با هــدف كسبـ

مى كند.

Dij= Dاتريس مقايسات زوجى گروهـى ارزش تـأثير راهبردهـا نسبت بـه هر معيار $\overline{P_{i j}}=\frac{\sum_{i=1}^{M_{j=1}^{N}} P_{i j}}{N}$

در نهايت يك نمودار علّى (اثر گذارى -اثريذّيرى) كـه شـامل

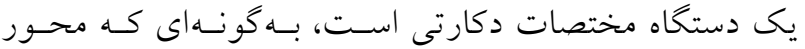
طولى آن برحسب مقادير R+J و محور عرضى آن بر حسبـ مدرج باشد، بر مبناى "جدول ترتيب نفوذ راهبردها بـر يكــيخر در ارتبـاط بـا مجمـوع معيارهـا" تشـكيل شـده، و موقعيت هر يك از راهبردهاى موجود با نقطهاى به مختصات
نشانخر اهميت (وزن) آن عامل در سيستم است. مقدار R بـراى

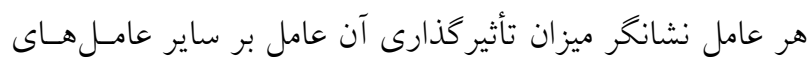
سيستم و مقدار J متناظر با آن بيانخر شـــت تأثيريـــيرى عامـل

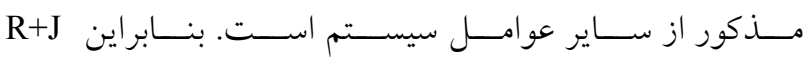

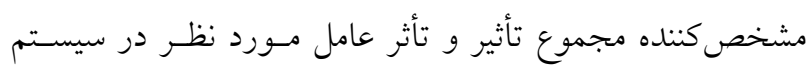
اسـت. بــهبـارتى، عامـل دارنـــه بيشـترين مقــدار R+J داراى بيشترين تعامل با ساير عوامل سيستم اسـتـ. مقـــار نهـايى تـأثر (فقط اثر گذارى) هر عامل بر مجموعه ديخر عوامل سيستم نيز از تغاضل R-J حاصل مىشود، به گونهاى كه: عامل، يك تأثير گذار قطعى است: عامل، يك تأثير يذير قطعى است: بدينترتيب متناسب با ميزان تأثير و تأثر هر معيار در ارتبـاط بـا

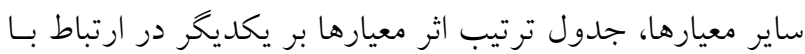
هدف بر آورد شد.

- تعيين اثر راهبردها بر يكديخر در ارتباط با هر معيار در اين مرحله نيز مانند مرحله قبل بهمنظـور تعيسين راهبردهـاى مؤثر و تعيين مقدار اتــر هـــــــــام از آنهـا، مــاتريس مقايسـات زوجى گروهى راهبردها نسبت به هر معيار (ماتريس D) مدنظر قرار گرفته و طى مراحل بيانشده (مراحل الف تـا ج)، جــداول ترتيب نفوذ راهبردها بر يكديخر در ارتباط با هر معيـار بـرآورد شد. در اينجا مشاهلده مىشـود كـه تأثيركـذارى هـر راهبـرد در ارتباط با هر معيار متفاوت است، بنابراين بـهمنظـور تعيسين اثـر راهبردها در دستيابى به هدف، تعيين اثر در ارتبـاط بـا مجمـوع معيارها طى مراحل زير مدنظر قرار كرفت. 
جدول r. ماتريس مقايسات زوجى راهبردها نسبت به هر معيار در ارزش همان معيار

\begin{tabular}{|c|c|c|c|c|c|}
\hline \multirow{6}{*}{$P_{i j}=$} & & \multicolumn{4}{|c|}{ Alt } \\
\hline & & $\mathrm{A}_{1}$ & $\mathrm{~A}_{2}$ & $\ldots$ & $\mathrm{A}_{\mathrm{m}}$ \\
\hline & $\mathrm{A}_{1}$ & $\mathrm{P}_{11}$ & $P_{12}$ & $\ldots$ & $P_{1 m}$ \\
\hline & $\mathrm{A}_{2}$ & $\mathrm{P}_{21}$ & $\mathrm{P}_{22}$ & $\ldots$ & $\mathrm{P}_{2 \mathrm{~m}}$ \\
\hline & $:$ & : & : & $:$ & : \\
\hline & $\mathrm{A}_{\mathrm{m}}$ & $\mathrm{P}_{\mathrm{m} 1}$ & $\mathrm{P}_{\mathrm{m} 2}$ & $\ldots$ & $\mathrm{P}_{\mathrm{mm}}$ \\
\hline
\end{tabular}

جدول r. ماتريس مقايسات زوجى ميانخين ارزش تأثير راهبردها در مجموع معيارها

\begin{tabular}{|c|c|c|c|c|c|}
\hline & & \multicolumn{4}{|c|}{ Alt } \\
\hline \multirow{5}{*}{$\overline{\mathrm{P}_{\mathrm{ij}}}=$} & & $\mathrm{A}_{1}$ & $\mathrm{~A}_{2}$ & $\ldots$ & $\mathrm{A}_{\mathrm{m}}$ \\
\hline & $\mathrm{A}_{1}$ & $\overline{\mathrm{P}}_{11}$ & $\overline{\mathrm{P}}_{12}$ & $\ldots$ & $\bar{P}_{1 m}$ \\
\hline & $\mathrm{A}_{2}$ & $\overline{\mathrm{P}}_{21}$ & $\overline{\mathrm{P}}_{22}$ & $\ldots$ & $\bar{P}_{\mathrm{Im}}$ \\
\hline & : & : & : & : & : \\
\hline & $\mathrm{A}_{\mathrm{m}}$ & $\overline{\mathrm{P}}_{\mathrm{m} 1}$ & $\overline{\mathrm{P}}_{\mathrm{m} 2}$ & $\ldots$ & $\bar{P}_{\mathrm{min}}$ \\
\hline
\end{tabular}

و در ادامه، ماتريس مقايسات زوجى اهميت معيارها نسـبت بـهـ

هدف (جدول 9) و اولويت راهبردها نسبت به تكتكى معيارهـا (جدول ( ) از نظر كروه بهدست آمد.

همجزنـان كــه در جــدول (9) ملاحظظـه مـى شــود نسـبت ناسازگارى در تمـام جــداول و مقايسـات زوجسى كمتـر از / / برآورد شده كه نشان از سازكارى مقايسات دارد (سب). در اين مرحله بهمنظور تعيين معيارهاى مؤثر و ميزان اثر آنها مطابق ادبيات تحقيق، با درنظركرفتن ماتريس مقايسـات زوجسى

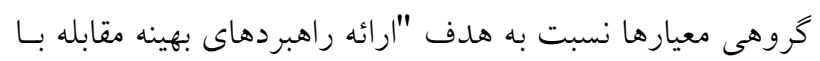
بيابانزايى" (جدول 9)، ماتريس M كه نشانكر شدت اثر نسـبى حاكم بر رابطههاى مستقيم موجود در سيستم است از رابطه (r) محاسبه و ماتريس S كه نشانكر شدت اثر نسبى حاكم بر روابط مستقيم و غيرمستقيم موجود در سيستم است از رابطه ثأبـرآورد شد. بدينترتيب متناسب با ميزان تأثير و تأثر هر معيار در ارتباط با ساير معيارها، جدول ترتيب اثر معيارها بر يكديخر در ارتباط
A:(R+J, R-J) نقاطى كه بالاى خط افقى قـرار گيرنـد نشـانكر راهبردهـاى اثريذير و نقاطى كه در سمت راست خط عمودى قرار كيرند نشانگر راهبردهاى اثر گذار هستند (شكل r).

نتايج با توجه به ادبيات تحقيق، در ابتدا بهمنظور دستيابى به معيارها و راهبردهاى مهم و اولويتدار از نظر گروه، از روش دلفى و تهيه

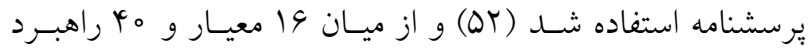
نهايى نظرخواهىشده بهمنظور مقابله با بيابانزايس، راهبردهـا و

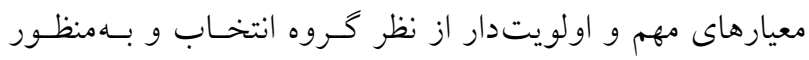
ترسيم نمودار سلسـلهمراتـب تصـميم گيـرى و تهيـه برسشـنامه مقايسات زوجى درنظر گرفته شدند (جداول fاو ه). يس از مشخصشدن معيارها و راهبردهاى مهم و اولويست دار از نظر كروه، ماتريس مقايسات زوجى هر متخصص شكل گرفـت 


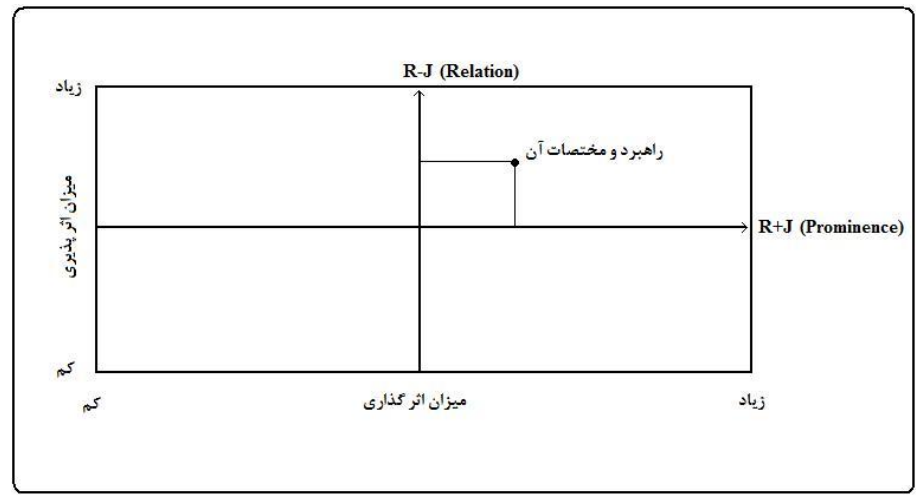

شكل r. نمودار علّى و نحوه نمايش راهبردها

مطابق شكل (Y) ملاحظه مىشود كه راهبرد "توسعه و احياء يوشش كياهى" (Arr) با شدت تأثير و تأثر (R+J=1/199)،

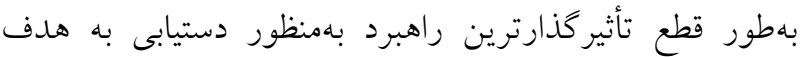

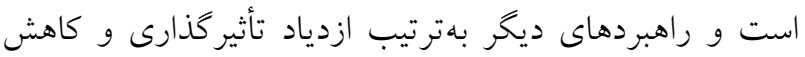
تأثيريذيرى، راهبردهاى "تغيير الكوى آبيارى و و اجراى نهاى

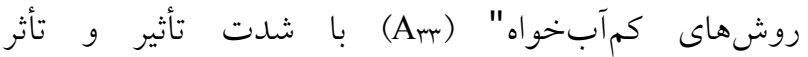

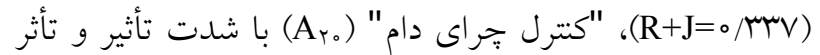

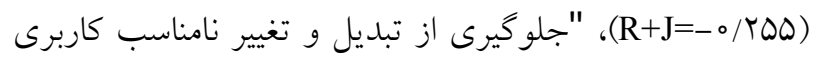

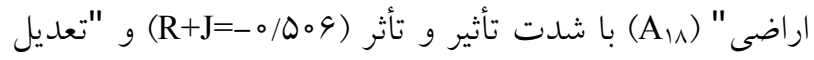

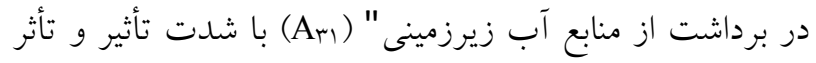

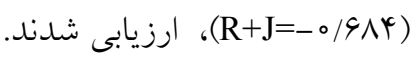

\section{بحث و نتيجه گيرى}

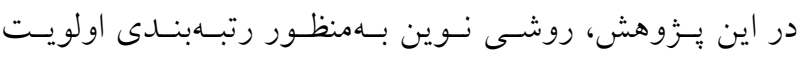

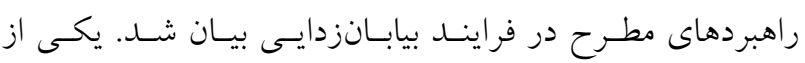

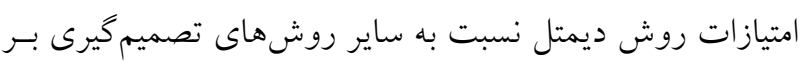

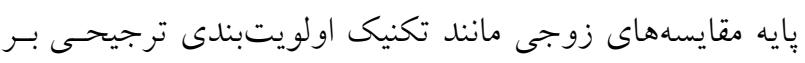

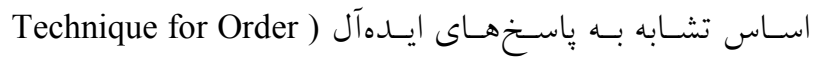
(TOPSIS $=$ Preference by Similarity to Ideal Solution (Dermutation) (م) (م) كه ارجحيـت معيارهـا را در اولويتبندى راهبردها بهمنظور دستيابى بـهـ هـدف درنظـ

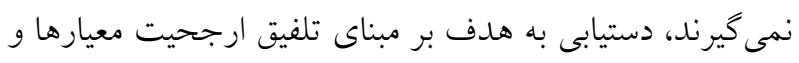

با هدف برآورد شد (جدول ^). مطابق جدول (N) مؤثرترين معيار در ارائه راهبردهاى بهينه مقابله با بيابانزايى، معيار تناسب و سازكارى با محيطزيست با شدت اثر كذارى (R-J=1/\% (C) خسارات محيطى و انسانى (C) ) با شدت اثركذارى ارزيابى شد. ابزارهاى علمى و تكنولوزى در دسترس (CD) با شدت اثر كذارى (R-J=-o/9V9) و معيارهاى

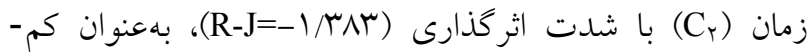
اثرترين معيارها بر آورد شدند.

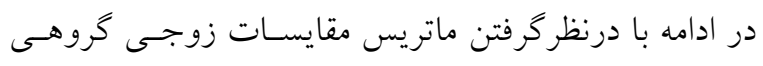

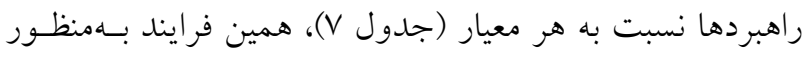

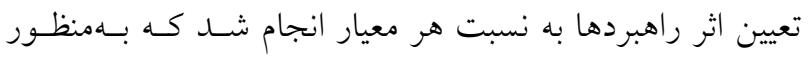

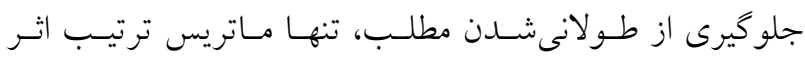

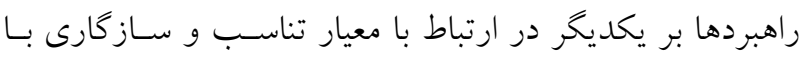
محيطزيست (C) ارائه مى شود (جدول 9). طبق اين جداول ملاحظـهـ شـد كـهـ بـر حسـب هـر معيــار،

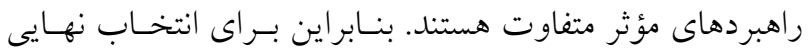

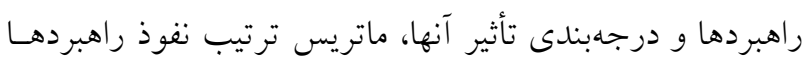

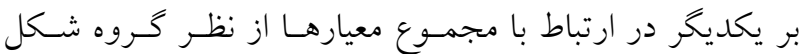

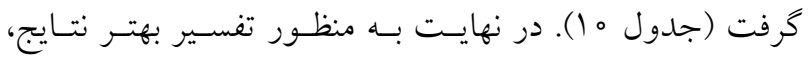

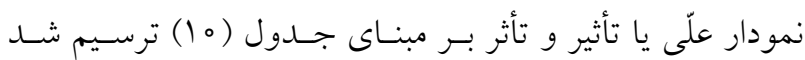
(شكل r). 


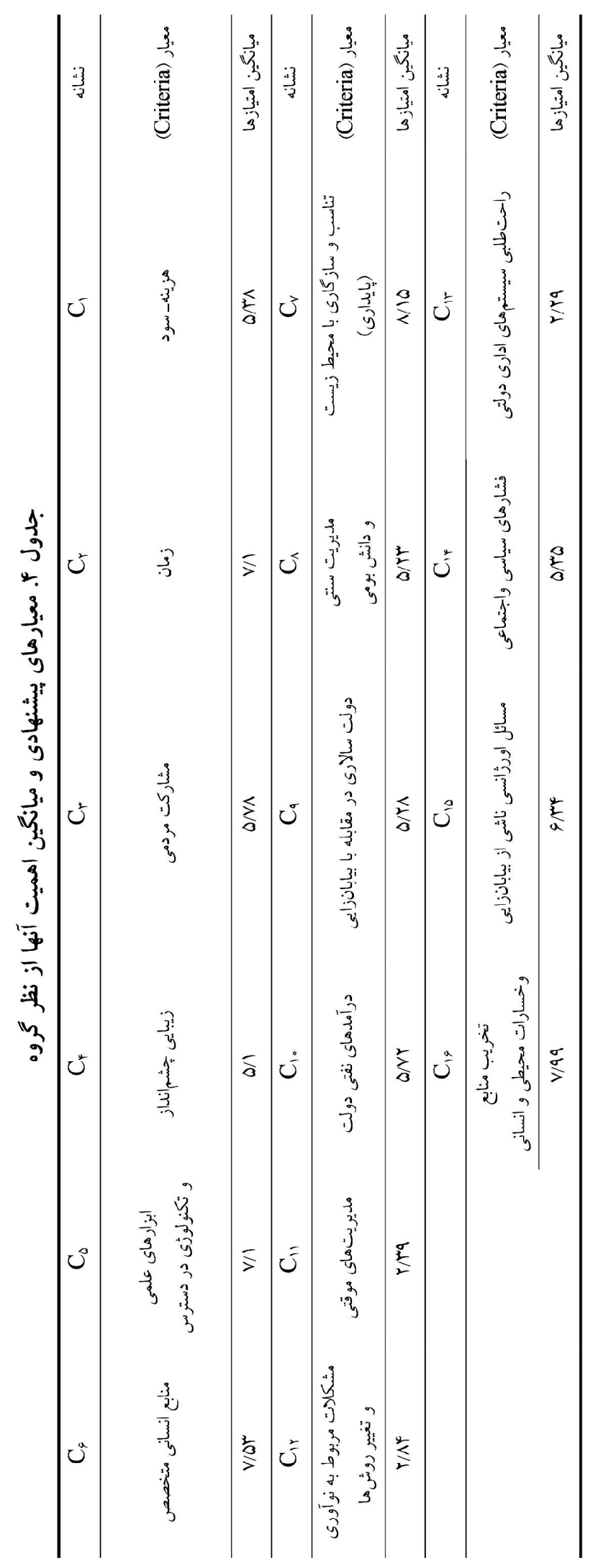


بومشناسى كاربردى / سال نهم / شماره جهارم / زمستان

\section{جدول ه. راهبردهاى بيشنهادى و ميانخين اولويت آنها از نظر گروه}

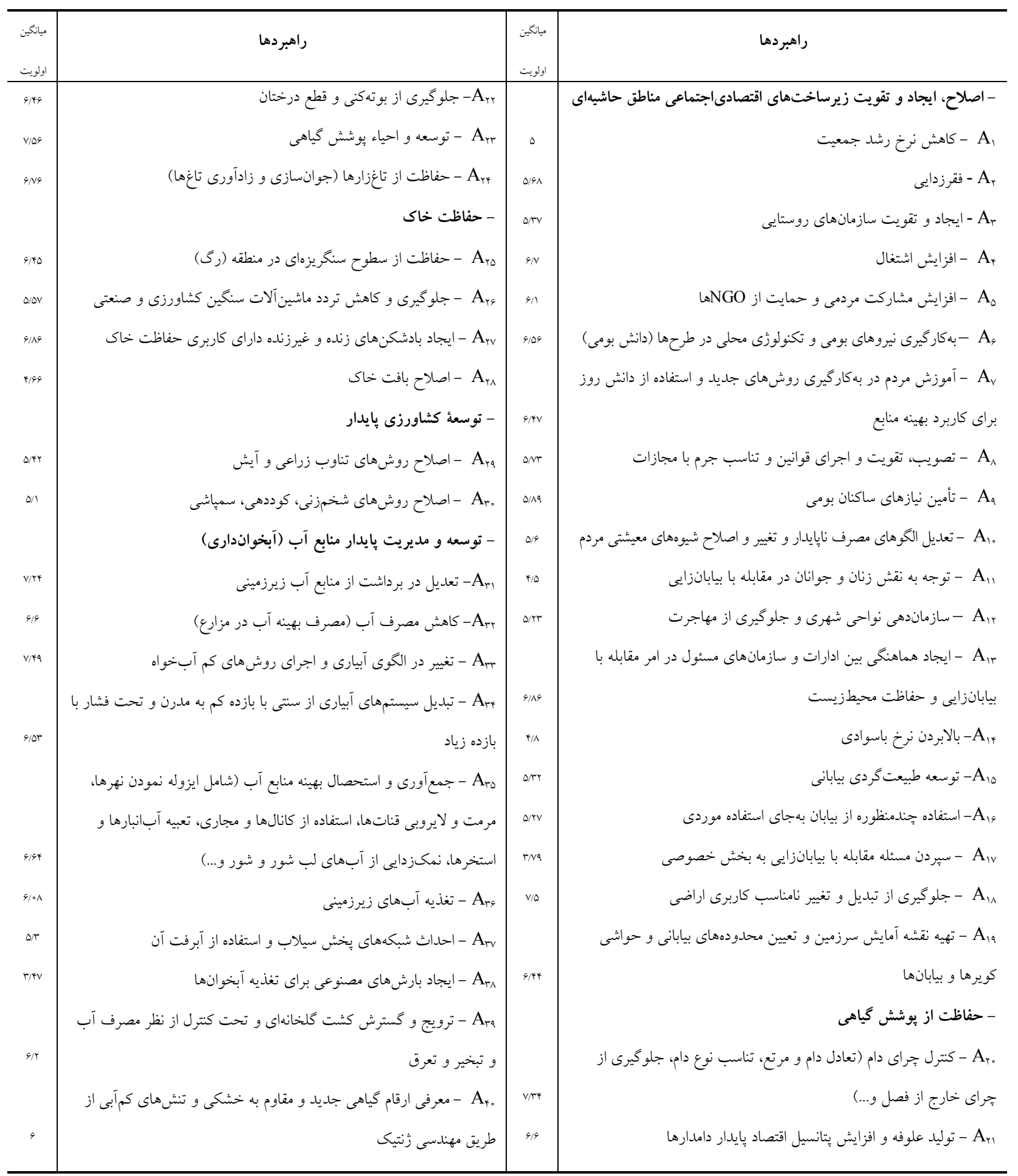


جدول و. ماتريس مقايسات زوجى گروهى معيارها نسبت به هدف "ارائه راهبردهاى بهينه مقابله با بيابانزايى"

\begin{tabular}{|c|c|c|c|c|c|}
\hline $\mathrm{C}_{Y}$ & $\mathrm{C}_{\Delta}$ & $\mathrm{C}_{\varphi}$ & $\mathrm{C}_{19}$ & $\mathrm{C}_{\mathrm{V}}$ & $\mathrm{G}^{*}$ \\
\hline 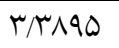 & r/DQYA & $r / \Delta \Delta \wedge \Lambda$ & $1 /$ YYOI & 1 & $\mathrm{C}_{\mathrm{V}}{ }^{* *}$ \\
\hline$r / \circ \wedge \circ Y$ & $r / \circ V V r$ & T/MTDD & 1 & $\circ / \Lambda \circ M I$ & $\mathrm{C}_{19}$ \\
\hline T/OYAV & INGYO & 1 & OKYAT & $\circ / \pi q \circ \wedge$ & $\mathrm{C}_{4}$ \\
\hline I/TIVA & 1 & $0 / 41 / 0 V$ & $\circ / K T Q \circ$ & $0 / 1919$ & $\mathrm{C}_{\Delta}$ \\
\hline 1 & - NQMA & $0 / 4 \wedge q 1$ & OMTYV & $\circ / 19 Q^{\circ}$ & $\mathrm{C}_{Y}$ \\
\hline
\end{tabular}

عنو ان هدف (ارائه راهبردهاى بهينه مقابله با بيابانزايى)

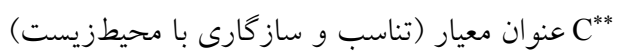

جدول V. ماتريس مقايسات زوجى گروهى راهبردها نسبت به معيار " تناسب و ساز گارى با محيطزيست"

\begin{tabular}{|c|c|c|c|c|c|}
\hline$A_{r 1}$ & $A_{r_{0}}$ & $A_{r r}$ & $A_{1 \wedge}$ & $A_{r r}$ & $\mathrm{C}_{\mathrm{V}}{ }^{*}$ \\
\hline ०/QYY० & $1 / T 9 V 9$ & $1 / \Delta V Y \Lambda$ & $1 / 11$ & 1 & $\mathrm{~A}_{\Gamma \mu}{ }^{* *}$ \\
\hline$|/ \mu \circ Y|$ & $1 / 090 \mathrm{~V}$ & TMRTr & 1 & $0 / 9009$ & $A_{1 \wedge}$ \\
\hline $1 / 0099$ & $1 / \pi \circ 99$ & 1 & OKYTIK & - /GMOA & $A_{r r}$ \\
\hline O/ASVT & 1 & O/ATAG & D/GTGV & $\circ / V \wedge \Lambda V$ & $A_{r}$ \\
\hline 1 & l/lQr。 & o/qkrk & ०/VGA。 & 1/०Vr。 & $A_{r 1}$ \\
\hline
\end{tabular}

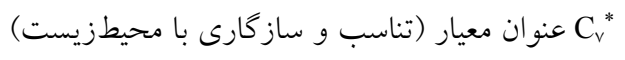

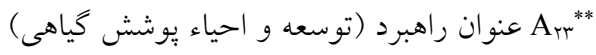

جدول ^^. ترتيب اثر معيارها بر يكديخر در ارتباط با هدف

\begin{tabular}{|c|c|c|c|c|c|c|c|}
\hline 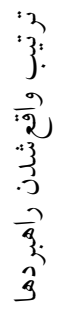 & 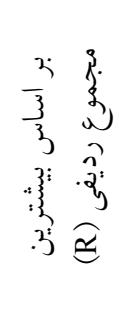 & $\begin{array}{l}3 \\
3: \\
3 . \\
0 \\
12 \\
3 \\
3 \\
.3 \\
\hat{9} \\
\hat{9} \\
\hat{3}\end{array}$ & $\begin{array}{cc}\begin{array}{c}3 \\
3\end{array} & 3 \\
3 & 5 \\
3 & 3 \\
3 & 3 \\
3 & 3 \\
3 & 5\end{array}$ & $\begin{array}{l}3 \\
3: \\
3 . \\
0 \\
12 \\
3 \\
3 \\
3 \\
\hat{9} \\
3 \\
3\end{array}$ & \begin{tabular}{l}
$\frac{3}{3}$ \\
$\frac{3}{3}$ \\
\multirow{2}{*}{}
\end{tabular} & $\begin{array}{l}2 \\
3: \\
3 \\
02 \\
12 \\
3 \\
3 \\
\overline{9} \\
3 \\
3\end{array}$ & $\begin{array}{l}\frac{3}{3} \\
\frac{3}{3} \\
\frac{1}{2}\end{array}$ \\
\hline $\mathrm{C}_{\mathrm{V}}$ & l/NDQY & $\mathrm{C}_{Y}$ & 1/AVTD & $\mathrm{C}_{\mathrm{v}}$ & T/TGYT & $\mathrm{C}_{\mathrm{v}}$ & $1 / \pi 099$ \\
\hline $\mathrm{C}_{19}$ & I/NYAS & $\mathrm{C}_{\Delta}$ & $1 / 0099$ & $\mathrm{C}_{Y}$ & $r / \mu \Delta \circ \Lambda$ & $\mathrm{C}_{19}$ & $1 / \Lambda \wedge V Y$ \\
\hline $\mathrm{C}_{\varphi}$ & $0 / 9799$ & $\mathrm{C}_{4}$ & 1/11VG & $\mathrm{C}_{\Delta}$ & $r / \mu I$ & $\mathrm{C}_{4}$ & $-0 / 1 \wedge V V$ \\
\hline $\mathrm{C}_{b}$ & $\circ / \Delta \wedge \mu \mid$ & $\mathrm{C}_{19}$ & - /DGIF & $\mathrm{C}_{19}$ & $Y / \circ \Delta \circ Y^{c}$ & $\mathrm{C}_{\Delta}$ & $-\circ / 9 \vee 9 \Delta$ \\
\hline $\mathrm{C}_{Y}$ & $0 / 49.1$ & $\mathrm{C}_{\mathrm{V}}$ & $0 / 4909$ & $\mathrm{C}_{4}$ & $T / \circ Y^{4} V D$ & $\mathrm{C}_{Y}$ & -I/TAKV \\
\hline
\end{tabular}


جدول 9. ترتيب نفوذ راهبردها بر يكديخر در ارتباط با معيار "تناسب و سازكارى با محيطزيست (C)

\begin{tabular}{|c|c|c|c|c|c|c|c|}
\hline $\begin{array}{l}3 \\
3 \\
3: \\
9 \\
92 \\
3 \\
3 \\
3 \\
\overline{9} \\
3 \\
3 \\
3\end{array}$ & $\begin{array}{cc}3 & 3 \\
3 & \vdots \\
3 & 0 \\
3 & 2 \\
3 & \vdots \\
3 & \widehat{2}\end{array}$ & 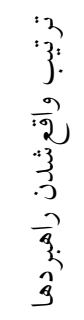 & $\begin{array}{cc}3 & 3 \\
3 & 3 \\
3 & 5 \\
3 & : 3 \\
3 & 3 \\
3 & =\end{array}$ & 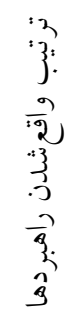 & $\begin{array}{c}\frac{3}{3} \\
\frac{3}{3} \\
\underset{E}{ \pm}\end{array}$ & 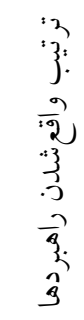 & $\begin{array}{l}\frac{3}{3} \\
\frac{3}{3} \\
\frac{1}{2}\end{array}$ \\
\hline$A_{r r}$ & $\circ / V \circ \Delta 1$ & $A_{r 1}$ & -/90Va & $A_{r r}$ & $1 / 09 \circ 0$ & $A_{r r}$ & $0 /$ II9V \\
\hline$A_{\curlywedge \wedge}$ & $0 / \Delta \wedge Y^{k}$ & $A_{r_{0}}$ & -/GIVD & $A_{r 1}$ & $1 / \circ \wedge 10$ & $A_{1 \wedge}$ & - IYAT \\
\hline$A_{r r}$ &.$/ 4 \wedge 99$ & $A_{r r}$ & & $A_{r_{0}}$ & 1/OYYG & $A_{r r}$ & -0/0YMT \\
\hline$A_{r 1}$ & o/kTtG & $A_{1 \wedge}$ & - \&ran & $A_{\curlywedge \wedge}$ & $1 / 0191$ & $A_{r_{0}}$ & $-\circ / Y \mid \circ \psi$ \\
\hline$A_{Y_{0}}$ & $\circ / 4 \circ V I$ & $A_{r r}$ & - MNQY & $A_{r r}$ & 1/O०H & $A_{r_{1}}$ & - \\
\hline & & با مجمو & تبا هر معيار & ير بردها. & هر راهبرد بر راهب & تأثير تأثير تأثير & 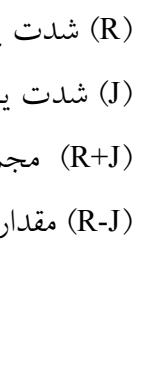 \\
\hline $\begin{array}{l}3 \\
3: \\
3 . \\
0 \\
22 \\
3 \\
3 \\
3 \\
\hat{9} \\
\hat{9} \\
3 \\
3\end{array}$ & $\begin{array}{cc}3 & 3 \\
3 & \vdots \\
3 & 0 \\
3 & .2 \\
3 & \vdots \\
3 & \approx\end{array}$ & $\begin{array}{l}2 \\
3: \\
3 \\
5 \\
52 \\
3 \\
3 \\
3 \\
\overline{3} \\
3.5 \\
3\end{array}$ & $\begin{array}{ll}3 & 3 \\
3 & 3 \\
3 & 3 \\
3 & 3 \\
3 & 3 \\
3 & =\end{array}$ & $\begin{array}{l}2 \\
3: \\
3 . \\
5 \\
32 \\
3 \\
3 \\
.5 \\
\overline{3} \\
3 \\
3 \\
3\end{array}$ & $\begin{array}{c}\frac{3}{3} \\
\frac{3}{3} \\
\stackrel{5}{ \pm}\end{array}$ & 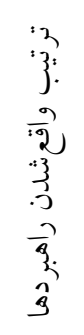 & $\begin{array}{l}\frac{3}{3} \\
\frac{3}{2}\end{array}$ \\
\hline$A_{r r}$ & $1 / 9909$ & $A_{1 \wedge}$ & ORTrV & $A_{r \mu}$ & $1 / 1990$ & $A_{r r}$ & T/YTYV \\
\hline$A_{r r}$ & $0 / 9991$ & $A_{r 1}$ & $0 / r q \wedge r^{r}$ & $A_{r r}$ & orrVY & $A_{r_{0}}$ & $-0 / 4 Y G 4$ \\
\hline$A_{r_{0}}$ & $-0 / \mu Y_{1}$ & $A_{r}$ & ०/^DG & $A_{r}$ & $-0 / T \Delta D Y$ & $A_{r r}$ & $-1 / \circ \Delta \psi \wedge$ \\
\hline$A_{\uparrow \wedge}$ & $-0 / q \mu q 4$ & $A_{r r}$ & $-\circ / \Gamma \Delta \wedge \vee$ & $A_{1 \wedge}$ & $-0 / 0.9 V$ & $A_{1 \wedge}$ & $-|/ r V Y|$ \\
\hline$A_{r 1}$ & $-1 / \circ \wedge T \Delta$ & $A_{r r}$ & -o/0ral & $A_{r 1}$ & $-0 / 9 \wedge 41$ & $A_{r 1}$ & $-1 / 4 \wedge \circ q$ \\
\hline
\end{tabular}

شدت يا ميزان تأثير گذارى هر راهبرد بر ساير راهبردها در ارتباط با مجموعه معيارها

شدت يا ميزان تأثيريذيرى هر راهبرد از ساير راهبردها در ارتباط با مجموعه معيارها مجموع تأثير و تأثر يا تعامل هر راهبرد با ساير راهبردها در ارتباط با مجموعه معيارها مقدار نهايى تأثير (اثر خذارى) هر راهبرد بر ساير راهبردها در ارتباط با مجموعه معيارها 


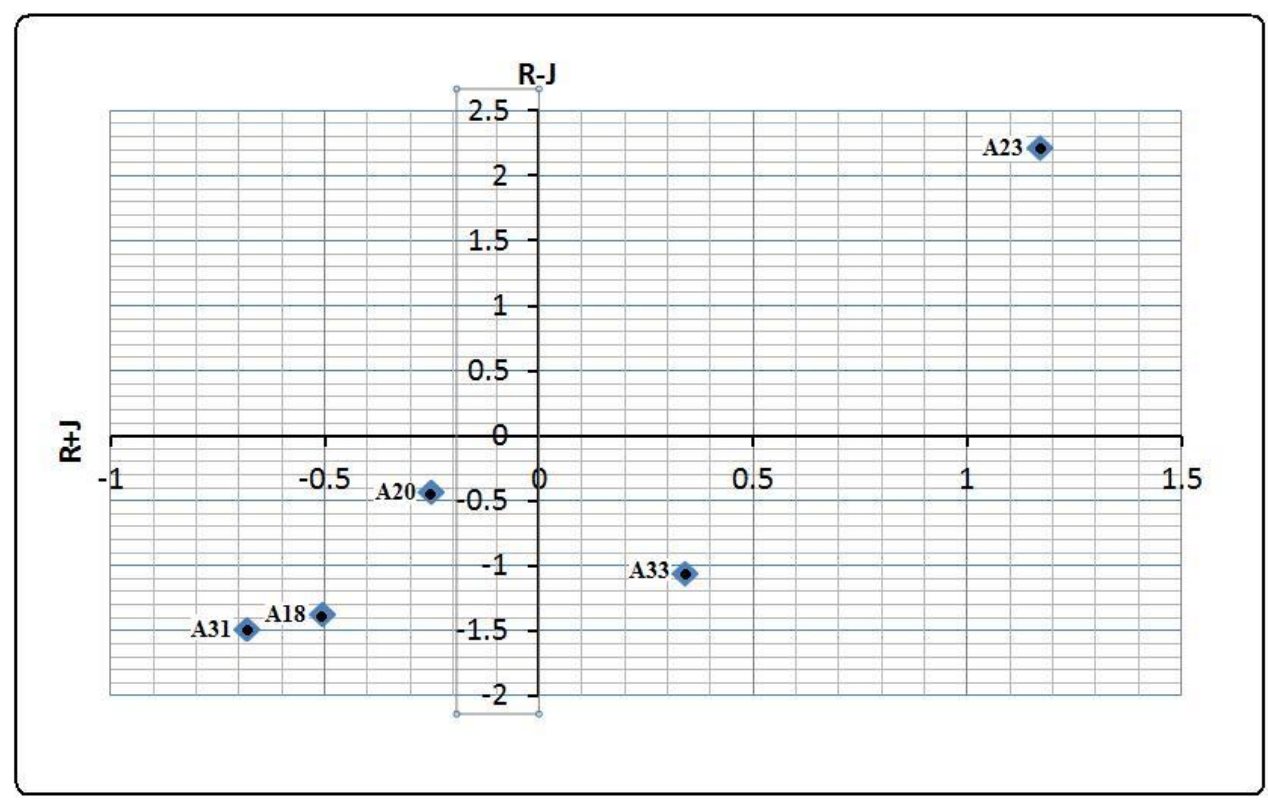

شكل r. نمودار تأثير و تأثر (علّى) راهبردهاى مقابله با بيابانزايى بر مبناى مجموعه معيارها

و راهبردها در سطوح تصميم گيرى است. در اين مدلها فقط معيارها و راهبردها با ساختار سلسلهمراتبى و از بالا به يايين سطحبندى شده و اوزان آنها مشخص مىشود، اما روابط داخلى بييجيده بين معيارها و راهبردها و تأثير آنها بر دستيابى به هدف نهايى لحاظ نمىشود. اين درحالى است كه در بسيارى از موارد نهتنها معيارها و راهبردها از هم مستقل نيستند، بلكه كاهى اوقات ميان بعضى از عوامل روابط و وابستخىهايى وجود دارد.

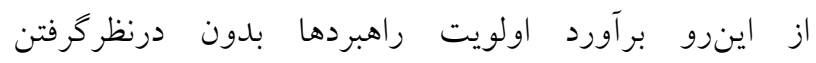
وابستخى هاى درونى منجر به نتايج غيرواقعى خواهد شد (YV). از ديخر معايب اين مدل ناديدهانخاشتن قضاوتهاى فازى تصميم گيران است. در اين رابطه بايد كفت بعضى از معيارها ساختار كيفى يا ساختار نامشخصى دارند كه نمىتوانند بهدقت اندازه كيرى شوند. در جنين مواردى بهمنظور دستيابى به ماتريس ارزشيابى مانند مدلهاى AHP فازى (OF) و تإيسيس فازى (\$9) مىتوان از اعداد فازى استفاده كرد. بنابراين مىتوان روشهاى اولويتبندى را با كاربرد اعداد فازى توسعه داد. از اينرو بهرغم اينكه رتبهبندى و ارزشهاى عددى بهدست آمده از مدلهاى تصميم گيرى در يكى منطقه تا حدودى مشابه
اولويت راهبردها است كه اين امر باعث شده نتايج حاصل از اين مدل با مدلهايى مانند روش رتبهبندى جمعى براى مقايسه ارزيابىهاى ترتيبى گزينهها بر اساس شاخصها ( Organisation Rangement Et Synthese de donnees Relationnelles (ORESTE (ELECTRE =Elimination et Choice Translating Reality) (Y) (Y)، روش ساختاريافته رتبهبندى ترجيحى براى غنى سازى Preference Ranking Organization Method For ) ارزيابىها PROMETHEE =Enrichment Evaluation

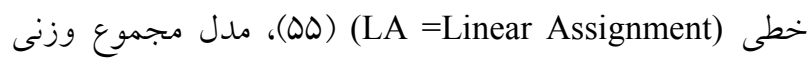
rצ (BORDA) (Y ) ب (WSM =Weighted Sum Model) و (ANP =Analytical Network Process) و تحليل شبكه كه اولويت راهبردها را بر مبناى اهميت معيارها مورد ارزيابى قرار مىدهند، همخوانى بيشترى داشته باشد، به اين معنى كه در مدلهاى مذكور هم مانند مدل ديمتل، راهبرد "توسعه و احياء يوشش كياهى" (Arr) بهعنوان راهبرد مؤثر

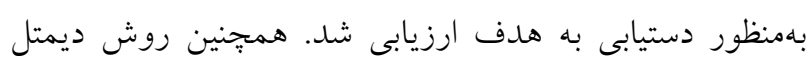
مانند روشهاى مذكور (بهجز روش تحليل شبكه)، واجد محدوديت درنظر نخرفتن وابستخى و ارتباط درونى بين معيارها 


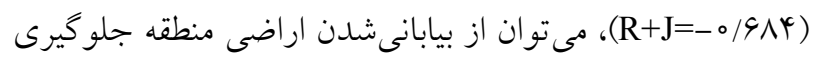
و نسبت به احياء اراضى تخريبيافته اقدام كرد. مطابق شكل r ملاحظه مىشود كه راهبرد "توسعه و احياء

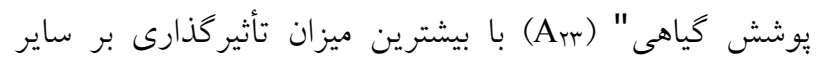

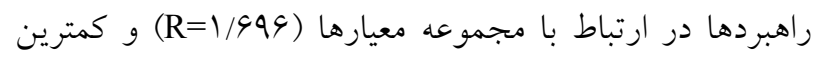

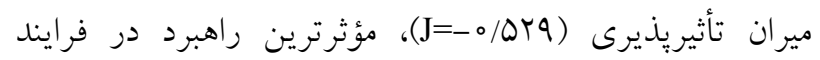
مقابله با بيابانزايى است. در اين رابطه، مطالعات ميدانى نشان

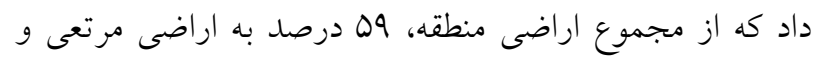

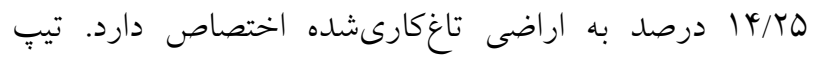

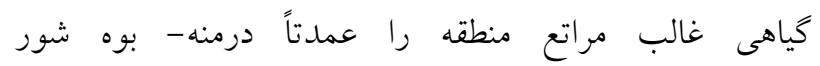
و درمنه- كوزينيا

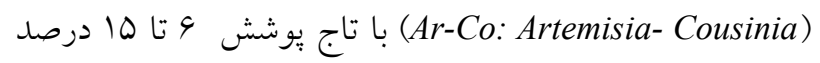
تشكيل مىدهد كه بهشدت تحت تأثير عملكردهاى انسانى در

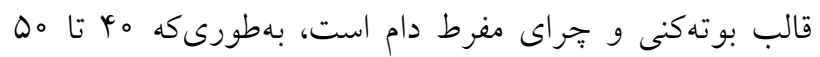

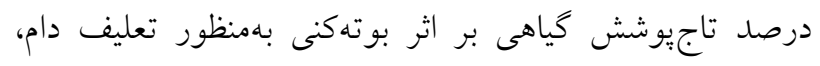

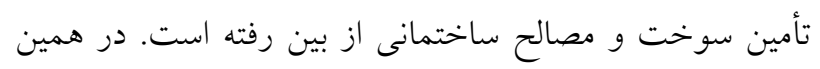

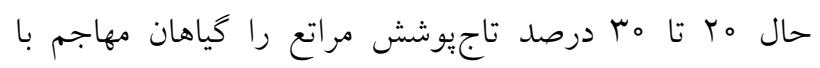

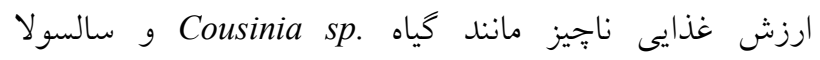
اشغال كرده است. بهطور كلى حدود 09 درصد ماند از عرصههاى منطقه مورد مطالعه را مراتع درجه جهار و بينج

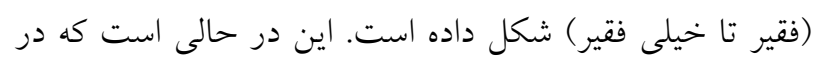

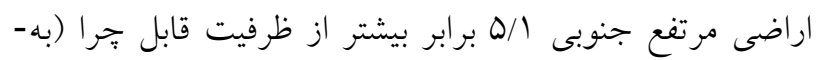

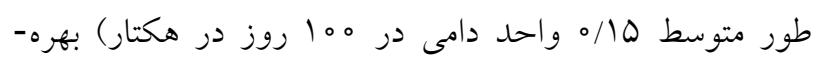

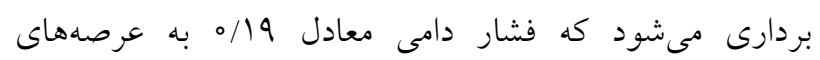

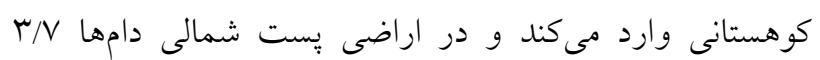
برابر بيشتر از ظرفيت مجاز تعليف مى كنند كه فشارى معادل

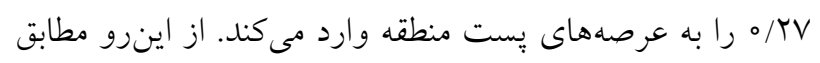

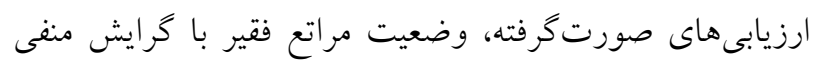

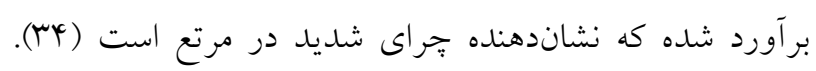

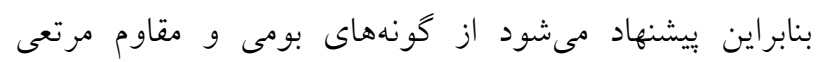

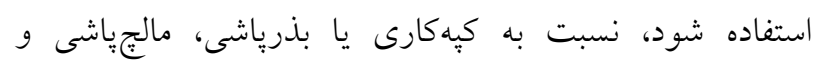

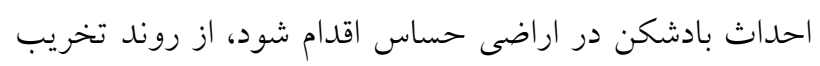

هستند، در عين حال همجنان با هم اختلاف دارند كه اين امر

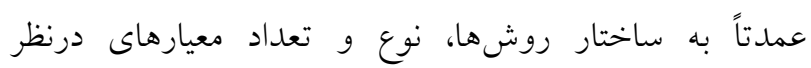

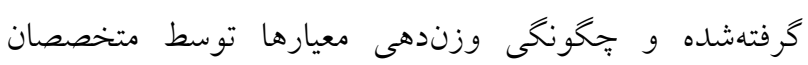

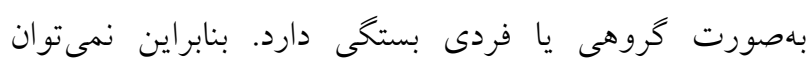

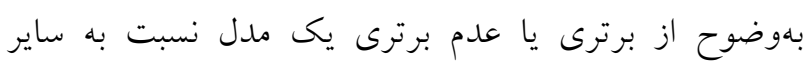

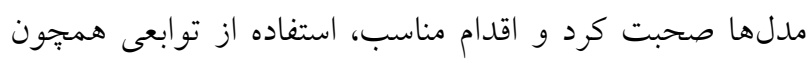

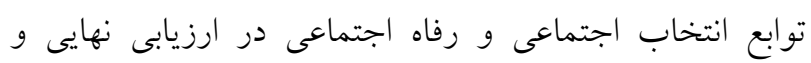

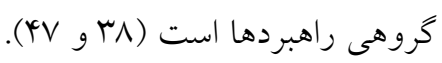

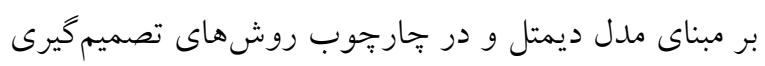

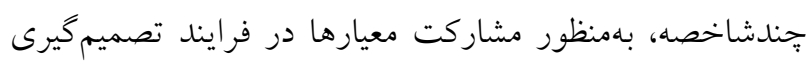
و تعيين اولويت نهايى، اهميت معيارها از جنبه اثر در فرايند

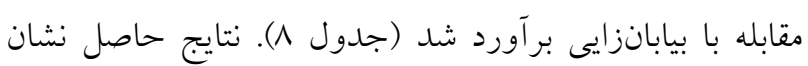

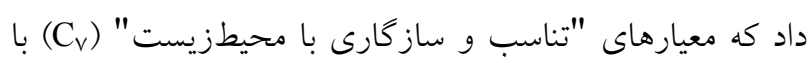

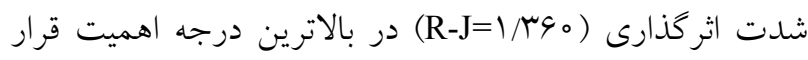

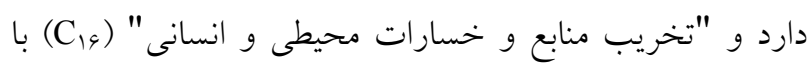

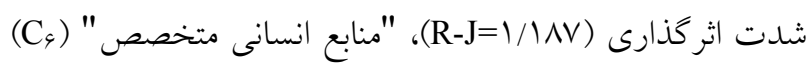

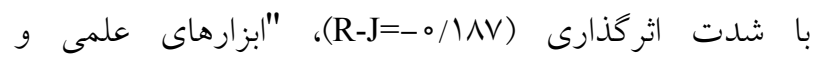

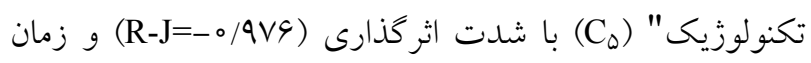

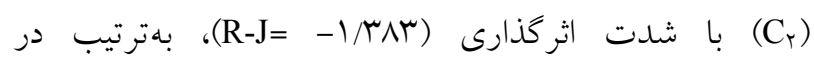
اولويتهاى بعدى قرار دارند كه نشانگر اهتمام كارشناسان و صاحبنظران نسبت به مسائل محيطزيست و جالشهاى نهاى مطرح در زمينه تخريب محيطزيست است. در ادامه بر مبناى اولويت

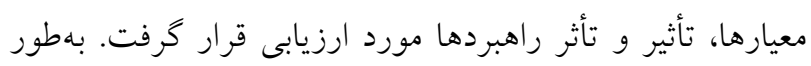

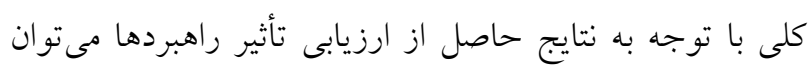

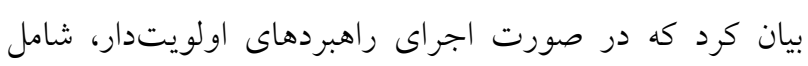

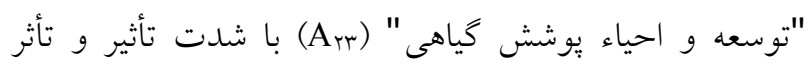

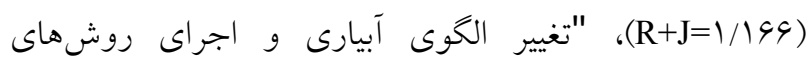

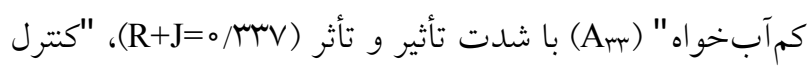
جراى دام" (

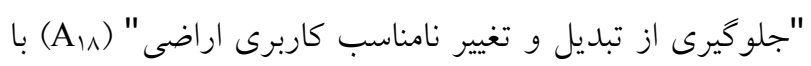

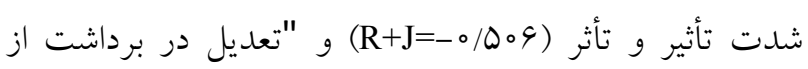

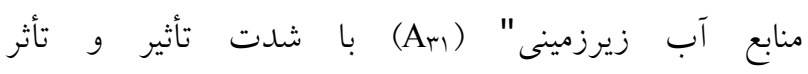




$$
\text { تاغزارها جلو گيرى و نسبت به احياء و بازسازى آنها اهتمام لازم }
$$

\section{منابع مورد استفاده}

1. Ali, T. A. 1998. Extent, severity and causative factors of land degradation in the Sudan. Journal of Arid Environment 38: 397-409.

2. Asgharpur, M. J. 2015. Group decision and game theory, operations research approach, 3rd edition. Tehran University, Tehran. (In Farsi)

3. Azar, A. and A. Rajabzadeh. 2018. Applied decision making with an approach of Multi-Attribute Decision Making (MADM), $6^{\text {th }}$ edition. Negah Danesh, Tehran. (In Farsi)

4. Bowyer, C., S. Withana, I. Fenn, S. Bassi, M. Lewis, T. Cooper, P. Benito and S. Mudgal. 2009. Land degradation and desertification. European Parliament, Policy Department A, Economic and Scientific Policy, Brussels, Belgium.

5. Briassoulis, H. 2019. Combating land degradation and desertification: the land-use planning quandary. Land 8(27): $1-26$.

6. Chauhan, A., A. Singh and S. Jharkharia. 2018. An ISM and DEMATEL method approach for the Analysis of barriers of waste recycling in India. Journal of the Air \& Waste Management Association 68(2): 100-110.

7. Cheshmberah, M., A. Naderizadeh, A. Shafaghat and M. Karimi Nokabadi. 2020. An integrated process model for root cause failure analysis based on reality charting, FMEA and DEMATEL. International Journal of Data and Network Science 4(2): 225-236.

8. Ding, X. F. and H. C. Liu. 2018. A 2-dimension uncertain linguistic DEMATEL method for identifying critical success factors in emergency management. Applied Soft Computing 71: 386-395.

9. Do, T. H. N. and W. Shih. 2016. Destination decision-making process based on a hybrid MCDM model combining DEMATEL and ANP: the case of Vietnam as a destination. Modern Economy 7: 966-983. http://dx.doi.org/10.4236/me.2016.79099.

10. Dou, Y. and J. Sarkis. 2013. A multiple stakeholder perspective on barriers to implementing China roHS regulations. Resources Conservation and Recycling 81: 92-104.

11. Falatoonitoosi, E., Z. Leman, S. Sorooshian and M. Salimi. 2013. Modeling for green supply chain evaluation. Mathematical Problems in Engineering 2013: 1-9. https://doi.org/10.1155/2013/201208.

12. Falatoonitoosi, E., A. Shamsuddin and S. Shahryar. 2014, Expanded DEMATEL for determining cause and effect group in bidirectional relations. The Scientific World Journal 2014: 1-7. .http://dx.doi.org/10.1155/2014/103846.

13. Fontela, E. and A. Gabus. 1976. The DEMATEL pilot survey. Futures 8(4): 379-389.

14. Food and Agriculture Organization (FAO). 1979. A provisional methodology for soil degradation assessment. FAO, Rome, Italy.

15. Gabus, A. and E. Fontela. 1972. World problems an invitation to further thought within the framework of DEMATEL. Battelle Geneva Research Centre, Geneva, Switzerland.

16. Gabus, A. and E. Fontela. 1973. Perceptions of the world problematique: communication procedure, communicating with that bearing collective responsibility (DEMATEL Report No. 1). Battelle Geneva Research Centre, Geneva, 
Switzerland.

17. Gabus, A. and E. Fontela. 1974. Structural analysis of the perceptions of the world problematique (DEMATEL Report No. 2). Battelle Geneva Research Centre, Geneva, Switzerland.

18. Gabus, A. and E. Fontela. 1975. Perceptions of the word problem matique: results of a pilot survey (DEMATEL Report No. 3). Battelle Geneva Research Centre, Geneva, Switzerland.

19. Gabus, A. and E. Fontela. 1976. The DEMATEL observer, DEMATEL Report No. 4. Battelle Geneva Research Centre, Geneva, Switzerland.

20. Geist, H. 2017. The Causes and progression of desertification. Routledge, London, UK.

21. Glantz, M. H. and N. S. Orlovsky. 1983. Desertification: a review of the concept. Journal of Desertification Control Bull 9: 15-22.

22. Govindan, K., R. Khodaverdi and A. Vafadarnikjoo. 2015. Intuitionistic fuzzy based DEMATEL method for developing green practices and performances in a green supply chain. Expert Systems with Applications 42(20): 7207-7220.

23. Grau. J. B., J. M. Anton, A. M. Tarquis, F. Colombo, L. Rios and J. M. Cisneros. 2010. Mathematical model to select the optimal alternative for an integral plan to desertification and erosion control for the Chaco Area in Salta Province (Argentine). Journal of Biogeosciences Discuss 7: 2601-2630.

24. Horng, J. S., C. H. Liu, S. F. Chou and C. Y. Tsai. 2013. Creativity as a critical criterion for future restaurant space design: developing a novel model with DEMATEL application. International Journal of Hospitality Management 33: 96-105.

25. Intergovernmental Science-Policy Platform on Biodiversity and Ecosystem Services (IPBES). 2018. Summary for policymakers of the assessment report on land degradation and restoration of the Intergovernmental Science-Policy Platform on Biodiversity and Ecosystem Services. IPBES Secretariat, Boon, Germany.

26. Jalalifar, S., K. F. Hafshejani and M. M. Movahedi. 2013. Evaluation of the effective barriers in GSCM implementation using DEMATEL method. Nature and Science 11(11): 95-102

27. Kabaday, N. and S. Dağ. 2020. Dealership performance evaluation in supply chain with DEMATEL and ELECTRE methods. Pamukkale University Journal of Engineering Sciences 26(1): 241-253.

28. Kashi, K. and V. Friedrich. 2014. Utilizing DEMATEL method in competency modeling. Forum scientiae Oeconomia 2(1): 95-106.

29. Khosravi, M. A., S. E. Najafi, H. Lak and M. Khosravi. 2014. A study of factors affecting customer's satisfaction with FUZZY DEMATEL method. Asian Journal of Research in Marketing 3(1): 46-60.

30. Lee, W. S., A. Y. Huang, Y. Y. Chang and C. M. Cheng. 2011. Analysis of decision making factors for equity investment by DEMATEL and analytic network process. Expert Systems with Applications 38: 8375-8383.

31. Lin, K. and C. Lin. 2008. Cognition map of experiential marketing strategy for ho spring hotels in Taiwan using DEMATEL method. In: Proceeding of $4^{\text {th }}$ International Conference on natural computation, IEEE. Jinan, China. Volume 01, pp. 438-442.

32. Reynolds, J. F and M. Stafford-Smith. 2003. Global desertification: Dd humans cause deserts? Geographical Review 93(3): 413-415.

33. Saaty, T. L. 2008. The analytical hierarchy and analytical network measurement processes: application to decisions under risk. European Journal of Pure and Applied Mathematics 1(1): 122-196.

34. Sadeghi Ravesh, M. H. 2008. Investigation of effective desertification factors on environmental degradation. Ph.D Thesis, Islamic Azad University, Tehran. (In Farsi)

35. Sadeghi Ravesh, M. H. 2013. Assessment of combat desertification strategies using Permutation method, case study: Khezrabad region, Yazd province. Journal of Environmental Management and Planning 3(4): 5-14. (In Farsi)

36. Sadeghi Ravesh, M. H. 2014. Evaluation of combat desertification strategies by using BORDA ranking model, case study: Khezrabad region, Yazd province. Journal of Environmental Management and Planning 4(2): 5-16. (In Farsi)

37. Sadeghi Ravesh, M. H. 2016. Decision making process to natural resources, 1st edition. Islamic Azad University Publication, Tehran. (In Farsi)

38. Sadeghi Ravesh M. H. 2018. Analysis of the desertification strategies derived from the decision-making models using social welfare function of B\&C. Desert Ecosystem Engineering Journal (DEEJ) 7(18): 37-48. (In Farsi)

39. Sadeghi Ravesh, M. H. 2019. Evaluation of de-desertification strategies In Ardekan- Khezr Abad plain by using Shannon Entropy method and ORESTE model. Quarterly journal of Environmental Erosion Research 4(8): 19-40. (In Farsi)

40. Sadeghi Ravesh, M. H. 2020. Desertification hazard zoning using Multi Attribute Utility Theory (MAUT) model. Environmental Researches 10(20): 177-194. (In Farsi)

41. Sadeghi Ravesh, M. H. and B. Jabalbarezi. 2019. Evaluation of combat desertification strategies by using MultiAttribute Utility Theory (MAUT), case study of Khezerabad region in Yazd Province. Journal on Environmental Technology and Sciences 21(8): 101-112. (In Farsi) 
42. Sadeghi Ravesh, M. H. and G. Zehtabian. 2013. Combat desertification strategies classification with using of Multi Attribute Decision Making (MADM) view point and Weighted Sum Model (WSM), case study: Khezrabad region, Yazd province. Journal of Pajouhesh \& Sazandeghi 100: 1-11. (In Farsi)

43. Sadeghi Ravesh, M. H. and H. Khosravi. 2014. Application of AHP and ELECTRE models for assessment of dedesertification strategies in central Iran. DESERT 19(2): 141-153.

44. Sadeghi Rravesh, M. H. and H. Khosravi. 2015. Application of Network Analysis Process (ANP) in assessment of combating desertification strategies. Desert Ecosystem Engineering Journal (DEEJ) 4(8): 11-24. (In Farsi)

45. Sadeghi Ravesh, M. H. and H. Khosravi. 2016. Evaluation of combat desertification strategies by using Individual Borda Ranking model. Desert Ecosystem Engineering Journal (DEEJ) 5(12): 109-121. (In Farsi)

46. Sadeghi Ravesh, M. H. and H. Khosravi. 2018. Assessment of de-desertification approaches using Multi Attribute Decision Making (MADM) and Principal Factor Analysis (PFA). Geographical Explorations of Desert Areas 6(1): 229-255. (In Farsi)

47. Sadeghi Ravesh, M. H. and H. Khosravi. 2019. Analysis of the alternatives to combat desertification derived from the decision-making models using the Social Choice functions, case study of Khezerabad region in Yazd Province. Journal of Environment Science and Technology (JEST), Online press. Available online at: jest.srbiau.ac.ir/article15145.html. (In Farsi)

48. Sadeghi Ravesh, M. H. and H. Khosravi. 2020. Identifying the most appropriate of combat desertification strategies by using the Eigenvector Method and the Vikor Model. Journal of Natural Environmental Hazards (In press). (In Farsi)

49. Sadeghi Ravesh, M. H. and M. Tahmoures. 2014. Evaluation of strategies to combat desertification using FTOPSIS model. Environmental Engineering and Sciences Quarterly 1(3): 79-94. (In Farsi)

50. Sadeghi Ravesh, M. H., G. R. Zehtabian, H. Ahmadi and H. Khosravi. 2012. Using analytic hierarchy process method and ordering technique to assess de-desertification strategies, case study: Khezrabad, Yazd, Iran. Carpathian Journal of Earth and Environmental Sciences 7(3): 51-60.

51. Sadeghi Ravesh, M. H., G. R. Zahtabian and M. Tahmoures. 2013. Vulnerability assessment of environmental issues to desertification risk, case study: Khezrabad Region, Yazd. Watershed Management Research 96: 75-87. (In Farsi)

52. Sadeghi Ravesh, M. H., H. Ahamadi, G. H. Zahtabian and M. Tahmoures. 2010. Application of Analytical Hierarchy Process (AHP) in assessment of de-desertification strategies. Iranian Journal of Range and Desert Research 17(1): 35-50. (In Farsi)

53. Sadeghi Ravesh, M. H., H. Khosravi and A. Abolhasani. 2016. Evaluation of combating desertification strategies using PROMETHEE Model. Journal of Geography and Geology 8(2): 1-14.

54. Sadeghi Ravesh, M. H., H. Khosravi and S. Ghasemian. 2015. Application of fuzzy analytical hierarchy process for assessment of combating-desertification strategies in the central Iran. Journal of Natural Hazard 75: 653-667.

55. Sadeghi Ravesh, M. H., H. Khosravi and S. Ghasemian. 2016. Assessment of combating strategies using the Liner Assignment method. Journal of Solid Earth 7: 673-683.

56. Sepehr, A. and N. Peroyan. 2011. Vulnerability mapping of desertification and combat desertification alternative ranking in Korasan-e-Razavi Province ecosystems with application of PROMETHEE model. Journal of Earth science researches 8: 58-71.

57. Shao, J., M. Taisch, M. O. Mier and E. Avolio. 2014. Application of the DEMATEL method to identify relations among barriers between green products and consumers. In: Proceedings of the 17th European Roundtable on Sustainable Consumption and Production-ERSCP. Portorož, Slovenia. pp. 1029-1040.

58. Sharma, S., S. Routroy and R. Desai. 2018. Retail location decision using an integrated DEMATEL-ANP method. International Journal of Operations Research and Information Systems 9(1): 51-65.

59. Su, C. M., D. J. Horng, M. L. Tseng, A. S. F. Chiu, K. J. Wu and H. P. Chen. 2015. Improving sustainable supply chain management using a novel hierarchical grey-DEMATEL approach. Journal of Cleaner Production, In Press. Available online at: http://dx.doi.org/10.1016/j.jclepro.2015.05.080.

60. Tzeng, G. and J. Huang. 2011. Multi attribute decision making: methods and applications. CRC Press, Boca Raton, Florida, USA.

61. United Nations (UN). 2015. Transforming our world, the 2030 agenda for sustainable development; resolution adopted by the general assembly on 25 September 2015; A/RES/70/1; 4th Plenary Meeting. United Nations, New York, USA.

62. United Nations Convention to Combat Desertification (UNCCD). 2017. The global land outlook, $1^{\text {st }}$ edition. United Nations Convention to Combat Desertification, Bonn, Germany.

63. Wu, K. Y., M. J. Zheng, S. C. Lu and Y. Y. Wu. 2015. Applying DEMATEL method to the study on sustainable management of low-carbon tourism for cultural heritage conservation. In: Recent advances in energy, environment, economics and technological innovation: Proceedings of the of the 4th International Conference on Development, 
Energy, Environment, Economics (DEEE '13), Proceedings of the 4th International Conference on Communication and Management in Technological Innovation and Academic Globalization (COMATIA '13). Paris, France. pp. 96102. Available online at: http://www.wseas.us/e-library/conferences/2013/Paris/DECO/DECO-13.pdf.

64. Yang, C. K., B. J. Lee and T. C. Lei. 2014. Assessing the influential factors of fire rescue using DEMATEL method. International Journal on Innovation, Management and Technology 5 (4): 239-243.

65. Yazdi, M., F. Khan, R. Abbassi and R. Rusli. 2020. Improved DEMATEL methodology for effective safety management decision-making. Safety Science 127: 1-17. 


\title{
Introducing a New Approach for Prioritizing Combating Desertification Strategies Based on Multi- Attribute Decision Making
}

\author{
M. H. Sadeghi Ravesh ${ }^{1 *}$
}

(Received: May 23-2020; Accepted: November 25-2020)

\begin{abstract}
Addressing desertification, due to its multi-criteria nature, increasing development, extensive and long-term impacts on natural resources and human populations, is necessary to achieve sustainable development. Therefore, for optimal utilization of facilities and limited funds allocated to this issue, evaluation of current strategies, based on different criteria is essential to avoid wasting national funds, while achieving better results. The current study used Decision Making Trial and Evaluation Laboratory (DEMATEL) to rank desertification strategies in the context of MultiAttribute Decision-Making (MADM) models. First, important and high-priority criteria and strategies were identified within the framework of MADM, using the Delphi method. Then, the final priority of strategies was determined using the DEMATEL method. Based on the obtained results, vegetation cover development and reclamation $\left(\mathrm{A}_{23}\right)$, change of irrigation patterns and implementation of low water demand methods $\left(\mathrm{A}_{33}\right)$, and livestock grazing control $\left(\mathrm{A}_{20}\right)$ were recognized as the most important combating desertification strategies in the region. Therefore, it is suggested to consider the obtained results and ranking in control plans to reduce the effects of desertification and reclamation of destructed lands.
\end{abstract}

Keywords: Combating Desertification, DEMETAL Method, Multi-Attribute Decision Making (MADM) Methods, Pairwise Comparisons

1. Associate Professor, Department of Environment, College of Agriculture, Takestan Branch, Islamic Azad University, Takestan, Iran.

*: Corresponding Author, Email: m.sadeghiravesh@tiau.ac.ir 